\title{
Weld defect frequency, size statistics and probabilistic models for ship structures
}

\author{
Peyman Amirafshari $^{1}$ (D), Nigel Barltrop ${ }^{1}$ (D), Martyn Wright ${ }^{2}$, Athanasios Kolios ${ }^{1}$ \\ ${ }^{1}$ University of Strathclyde, Department of Naval Architecture, Ocean and Marine \\ Engineering, Glasgow, United Kingdom, 'Lloyd's Register EMEA, Southampton, United \\ Kingdom
}

Phone: +44 7788953327, email: peyman.afshari@gmail.com

\section{Abstract}

Ships undergo cyclic loading which combined with weld defects can cause fatigue failure. Remaining fatigue life of structures containing defects can be estimated using the defect size. The defect data for ships is non-existent in literature or belong to old offshore structures. In this research, the data collected from two ships are presented. The statistical analysis of the data shows that the Hybrid Laser Welding has lower defect rates than other common arc welding processes indicating that less quality control inspection may be allowed. The defect length values from the studied ships were smaller than those from offshore structures.

\section{Key words}

Weld defects; Cracks size; Weld defect statistics; Probabilistic models; Fracture Mechanics

\section{Introduction}

Ship hull structures consist of thousands of pieces of steel components joined together through welded connections. However, formation of weld defects is inherent to this joining technology. These defects can grow into propagating fatigue cracks under application of cyclic stress. Traditionally, the so-called S-N curve method is used for the fatigue design of welded joints, which is typically applicable to structures containing only small defects; i.e. $0.2 \mathrm{~mm}$ sharp weld toe defect [1]. Such quality level is assumed to be achieved by practicing an effective quality control process at the shipyard through appropriate Non-destructive Testing (NDT) methods [2]. In reality, only a limited number of welded joints are inspected on a sampling basis [3]. Therefore, the presence of larger defects than those found in the inspections of the fabricated ship is highly likely. Damage-tolerant design philosophy which 
considers inspectability of the structure has been successfully adopted in ship hull structures given the highly redundant nature of these structures [4]. However, there have been considerable efforts to optimise the inspection strategy on these structures in order to improve safety and reduce inspection and maintenance costs [5]. These methods are commonly based on fracture mechanics. Probabilistic fracture mechanics, which calculates the reliability of the structure and the resulting failure risk, has been very popular recently. These methods require reliable estimation of weld defect frequency and size data. However, such data for ship hull structures is virtually non-existent in the public domain. Thus, defect size data from offshore oil platforms has been used instead, which goes back to 1980s and 1990s. Since then, the welding technology has improved both in terms of process type and quality control measures [6-8], therefore, this data may not be representative of modern ship structures, as the welded joints in ship structures are different from other structures including offshore support structures.

The aim of this paper is to investigate the defect frequency and size statistics of welded joints in ship hull construction by analysing NDT data collected from inspection of two recently built ships and analysed using the Maximum Likelihood Estimate (MLE). Furthermore, these results are compared with those from literature. The results obtained in this paper are novel and a valuable input for deterministic and probabilistic engineering critical assessment (ECA), risk and reliability analysis and weld quality assurance (QA)/ quality control (QC) of hull structures and is the first time that such data and probabilistic models for ship construction are derived.

\section{Literature review}

\subsection{Weld Defects}

Figure 1 illustrates common weld defect types. They include Cracks (Longitudinal and Transverse), Porosity (also known as Cavity), Undercut, Lack of Fusion (LOF), Lack of Penetration (LOP) and Solid Inclusions (SI). ISO6520 provides a detailed description of flaw and defect types [9]. It should be noted that there is a distinction between flaw and defect: a flaw is considered any weld imperfection, but a defect is an unacceptable flaw. 


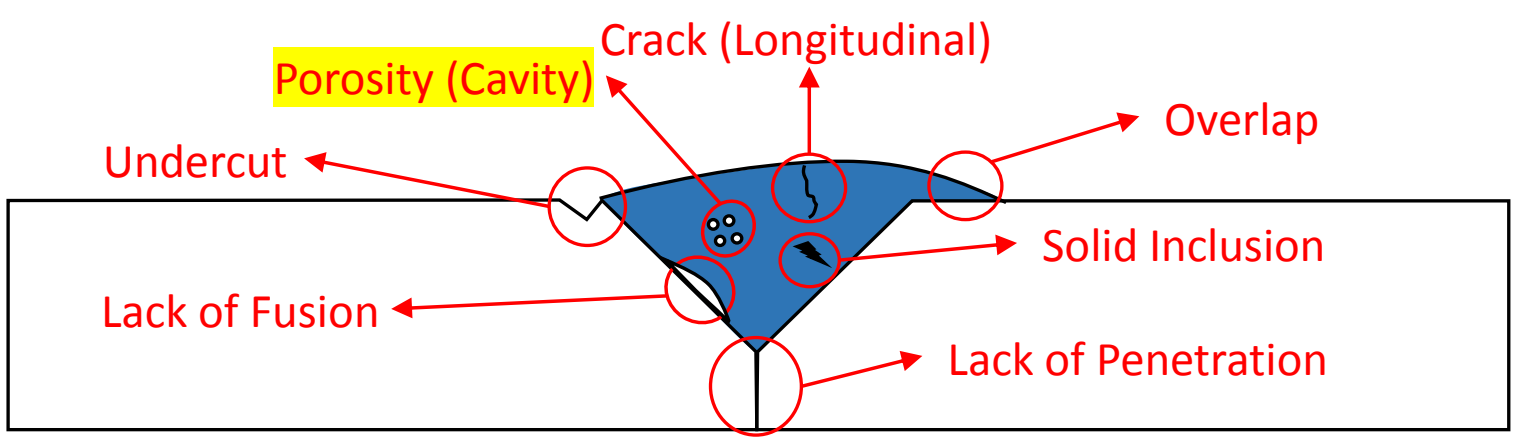

Figure 1 Common Weld defects

\subsection{Significance of weld defects}

The significance of weld defects is considered in relation to the static ultimate strength of the structure and the fatigue performance of the joint. The resistence of a butt welded joint is adequate for static loads. That is since the ultimate strength of deposited metal is higher than that of the base metal, and the weld metal normally has reinforcement. Hence, small welding defects will have little effect on static strength [10].

Considerable effort has been made to study the effect of various types of weld imperfections on the fatigue performance of common welded joint types. The body of knowledge has been built into "IIW Guidance on Weld Quality in Relationship to Fatigue Strength" [11] and "ISO 20273 Guidance on Weld Quality in Relationship to Fatigue Strength" [12]. Above guidelines provide provisions for assessment of such defects with a particular focus on nonplanar defects. Planar defects are assessed using Fracture Mechanics and references are made to standards such as BS7910 [13].

The effect of all types of misalignment can be considered using a magnification factor (increase of general stress level) [14]. Where the defect is located at the location of structural discontinuity (e.g. weld toe), the fatigue resistance is decreased by the additive notch effect [14]. If the defect is not located at the structural discontinuity, the notches are in competiton (competitive notch effect). Both notches need to be considered separately. The fatigue life is considered to be governed by the notch giving the lowest fatigue life [14]. Table 1 describes the defects, their effects on structural integrity and the appropriate assessment methods.

Table 1 Weld imperfections categories

\begin{tabular}{|c|c|c|c|}
\hline \multicolumn{2}{|c|}{ Effect of imperfection } & Type of imperfection & Assessment \\
\hline \multicolumn{2}{|c|}{$\begin{array}{l}\text { Rise of general stress } \\
\text { level }\end{array}$} & Misalignment & $\begin{array}{l}\text { Formulae for effective stress } \\
\text { concentration, refer to [11] }\end{array}$ \\
\hline \multirow{2}{*}{$\begin{array}{l}\text { Local } \\
\text { notch } \\
\text { effect }\end{array}$} & Additive & Weld shape imperfections, undercuts & Relevant table in [11] \\
\hline & Competitive & $\begin{array}{l}\text { Porosity and solid inclusions not near } \\
\text { the surface (Volumetric flaw) }\end{array}$ & Relevant table in [11] \\
\hline \multicolumn{2}{|c|}{$\begin{array}{l}\text { Crack-like } \\
\text { imperfection }\end{array}$} & $\begin{array}{l}\text { Planar flaws: Cracks, lack of fusion, and } \\
\text { lack penetration }\end{array}$ & Fracture Mechanics \\
\hline
\end{tabular}




\subsection{Common Welding Processes in ship production}

A number of welding processes are used in ship production. Detailed reporting on the selection of the welding process is not the intention of this research. Commonly used welding processes and weld types in ship hull fabrication are given in Table 2 and Figure 2.

Table 2 Typical weld types and processes in shipbuilding $([15,16])$

\begin{tabular}{|l|l|l|l|l|}
\hline No. & Component & Weld type & Process & Remarks \\
\hline 1 & Panel plate to panel plate & Horizontal Butt (Seam) & One-sided SAW & Automatic \\
\hline 2 & Longitudinal member to panel & Fillet & FCAW, HLAW & Automatic \\
\hline 3 & Double bottom inside & Fillet & FCAW & Semi-automatic \\
\hline 4 & Side shell & Transverse Butt (Butt) & FCAW, EGW & Semi-automatic \\
\hline 5 & $\begin{array}{l}\text { Longitudinal member to } \\
\text { Longitudinal member }\end{array}$ & Transverse Butt (Butt) & One-sided FCAW & Semi-automatic \\
\hline 6 & $\begin{array}{l}\text { Tank top plate to Hopper tank } \\
\text { plate and bulkhead }\end{array}$ & Fillet & FCAW & Semi-automatic \\
\hline 7 & $\begin{array}{l}\text { Tank top plate to tank top } \\
\text { plate }\end{array}$ & Horizontal Butt (Seam) & One-sided SAW & Automatic \\
\cline { 5 - 5 } & & & One-sided GMAW & $\begin{array}{l}\text { Automatic } \\
\text { GMAW }\end{array}$ \\
\hline
\end{tabular}
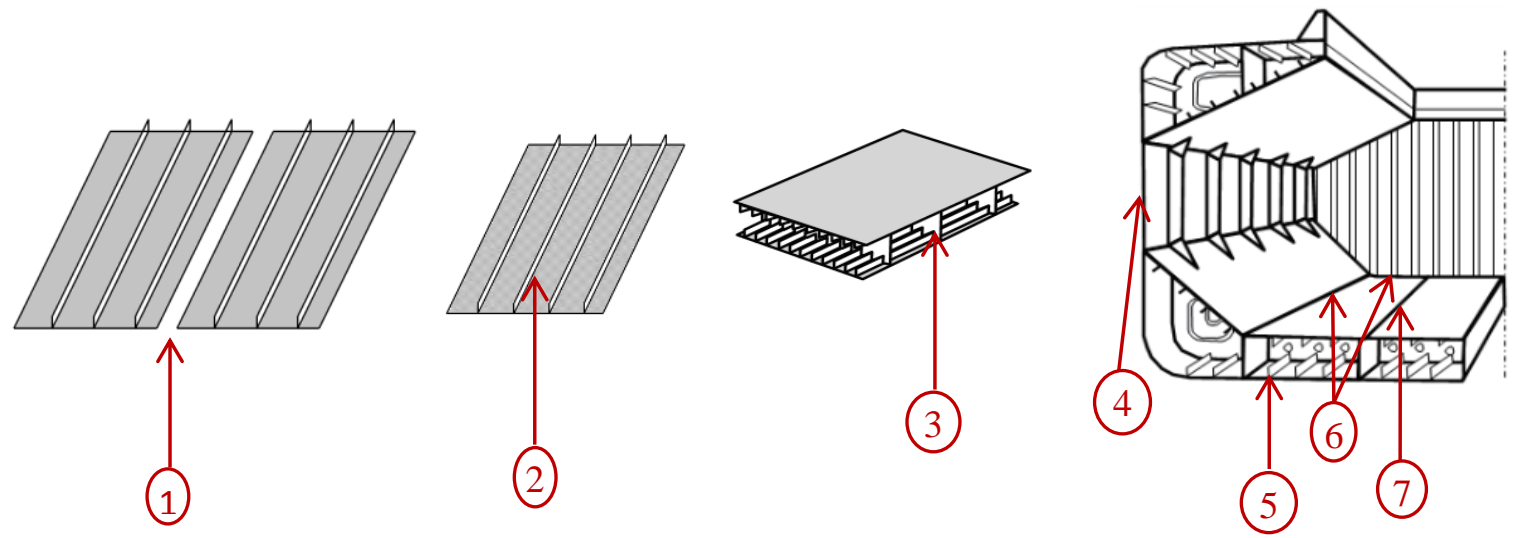

Figure 2 Typical weld types application in shipbuilding $([15,16])$

Most commonly used welding processes in the shipbuilding industry are flux-cored arc welding (FCAWs), submerged arc welding (SAW), double-sided and one-sided, automatic, portable welder, line welder, semiautomatic, and robotic (Table 2). FCAWs are popular, as they offer higher deposition rates over other types of filler metals, thus improving welding efficiency [16].

Since hull structures have many confined areas that are difficult to access, one-sided welding by FCAW is the common chioce of welding proccess. SAW process is particularly used for onesided welding of butt joints of large shell plates [16]. Hybrid laser-arc welding (HLAW) combines laser with an arc process in the same melted pool resulting in a process which has the benefits of both processes. 
HLAW has been increasingly used in shipbuilding due to its merits over the arc welding: Higher welding speed and penetration depth, compared with arc welding alternatives such as Gas Metal Arc Welding (GMAW) or SAW, are particularly important: the net heat input can be reduced, resulting in lower distortion, making the process an efficient choice for the welding of long seam welds joining plates or sections, etc. The costs related to subsequent distortion correction and rectification are also reduced [17].

\subsection{Influencing variables}

A crucial step in statistical analysis of the flaw frequency and size data is to determine the influencing variables. Type, frequency, and size of fabrication flaws depend on a number of variables such as joint type, welding process, welding position, welding procedure, restraint, material, welding location (workshop, site weld) and access [18-20]. A report based on a survey from experts [20], suggests that welder's skill is responsible for $27 \%$ of all repair rates across all industries followed by welding position (e.g. position, accessibility) at 16\%, thickness/number of runs at $6 \%$ and welding process at $6 \%$. The paper also reports that, in terms of joint type, $10 \%$ of defects are found among butt welds and $90 \%$ among fillet welds. In terms of specific weld runs, $75 \%$ occur in root runs and $25 \%$ in fill or cap. Not all these variables are individually controllable/assessable within inspection planning. For example, welder's skill is very difficult to quantify and is normally verified through an approval of competency procedure.

In reality, there is a correlation between these variables. For example, submerged arc welding is limited to the flat position with good access, or MMA process is only performed where access is restricted. Some of the variables such as welder's skill and weld variables (heat input, electrode type, welding speed and etc.) are hard to quantify at a large scale, thus, only the welding process is considered in this paper.

\subsection{NDT reliability}

Common conventional NDT methods used in ship production are listed in Table 3. NDT methods can be categorised into; surface testings, which are suitable for detection of surface breaking flaws and volumetric testings which can detect embedded flaws as well as surface breaking flaws.

Table 3 Common conventional NDT methods

\begin{tabular}{|l|l|}
\hline Volumetric Testing & Ultrasonic Testing (UT) \\
\cline { 2 - 2 } & Radiography Testing (RT) \\
\hline \multirow{3}{*}{ Surface Testing } & Visual Testing (VT) \\
\cline { 2 - 2 } & Magnetic Particle Testing (MPT) \\
\cline { 2 - 2 } & Dye Penetrant Testing (DPT) \\
\hline
\end{tabular}


Selection of the NDT method affects the detection probability and in turn the actual flaw statistics. Table 4 gives examples for some NDT scenarios. As an example, UT exhibits better probability of detection for planar defects and detects smaller planar defects than RT. RT is very reliable in detecting nonplanar defects and surface NDT methods show very good capabilities in detection of surface breaking flaws.

\begin{tabular}{|c|c|c|c|c|c|c|c|}
\hline \multirow{3}{*}{$\begin{array}{l}\text { Defect } \\
\text { height }\end{array}$} & \multicolumn{7}{|l|}{ POD } \\
\hline & \multicolumn{5}{|l|}{ RT [21] } & \multirow{2}{*}{$\begin{array}{l}\text { UT for } \\
\text { cracks } \\
{[22]}\end{array}$} & \multirow[b]{2}{*}{$\begin{array}{l}\text { Surface NDT } \\
\text { for cracks: } \\
\text { weld ground } \\
\text { flushed and } \\
\text { good } \\
\text { condition } \\
\text { environment } \\
\text { [22] }\end{array}$} \\
\hline & porosity & $\begin{array}{l}\text { solid } \\
\text { Inclusion }\end{array}$ & $\begin{array}{l}\text { lack of } \\
\text { penetration }\end{array}$ & $\begin{array}{l}\text { lack } \\
\text { of } \\
\text { fusion }\end{array}$ & cracks & & \\
\hline $\begin{array}{l}\text { Probability } \\
\text { at } 2.5 \mathrm{~mm}\end{array}$ & 0.71 & 0.84 & 0.45 & 0.74 & 0.32 & 0.75 & 0.93 \\
\hline $\begin{array}{l}\text { Probability } \\
\text { at } 10 \mathrm{~mm}\end{array}$ & 0.94 & 0.97 & 0.72 & 0.86 & 0.44 & 0.82 & 0.97 \\
\hline
\end{tabular}

\subsection{Defect rates}

Defect rate is a crucial factor in the calculation of the total reliability of a structure [18]. In a reliability assessment based on fracture mechanics, a defect size probability distribution is used to calculate the (conditional) probability of failure due to the presence of a defect.

The defect rate is subject to high uncertainty. QA/QC departments of manufacturers tend to work with repair rates. Repair rates are generally defined as percentage values. The methods used to calculate such values may vary. Commonly, these are calculated as the fraction of the length of repair over the total weld length, whereas others define this as the number of repaired welds over the total number of welds. The former provides a lower repair rate and may be preferred by manufacturers. A study by [20], based on a survey gathered from TWI's industrial members', reports that average repair rates range from 0.5 to $10 \%$ depending on the industry sector. For offshore structures the reported value is $2 \%$. Baker et al. found that defect rate as a ratio of defect length to total length of weld, lies in the range 0.010 to 0.014 [23]. They also found that defect rates for different yards are found to be radically different. [24] reports that there are 3.65 microscopic surface breaking defects of all sizes per pressure vessel. [25] found the defect rate to be 16 defects per metre, including rather small cracks. Marshal reported the defect rate of 0.7 per meter in a North Sea structure [26]. Data from 
[27] suggests a defect rate of 0.075 considering defect rate as mean number of defects per inspection for surface breaking cracks. Summary of reviewed defect rates from literature are given in Table 5. It is apparent from comparison of the defect rates that values vary significantly across the data sources. One reason is the way the defect rate is specified i.e. number of defects versus weld length, number of defects versus number of joints, or total defect length versus total inspected length. The second reason is the target defect type: if the data is acquired from a manufacturing quality control process, commonly all the defect types are treated the same way, whereas if the inspection is part of an integrity assessment typically planar defects are of interest. The third key factor is reliability of the NDT method: as described above, some NDT methods are less effective than others for certain defect types and sizes. For instance, MPT and Eddy Current (EC) testing are more reliable for detection of surface breaking flaws than UT but cannot detect embedded flaws. They are also capable of detecting smaller defect sizes than UT. RT is not generally reliable for detection of planar defects but exhibit good efficiency for detection of pore cavities [13]. Therefore, when comparing defect rates from deferent sources it is vital to account for the above factors to avoid misinterpretation of defect rates.

Table 5 Defect rates from literature

\begin{tabular}{|c|c|c|c|c|c|}
\hline Investigator & Joint & Defect type & NDT Type & Sample & Defect rate \\
\hline$[27]$ & $\begin{array}{l}23 \text { jacket } \\
\text { structures }\end{array}$ & $\begin{array}{l}\text { Fabrication } \\
\text { Cracks }\end{array}$ & MPT & 2386 & $\begin{array}{l}0.09 \text { (crack per } \\
\text { inspection) }\end{array}$ \\
\hline [20] & $\begin{array}{l}\text { Offshore } \\
\text { structures }\end{array}$ & Defects & $\begin{array}{l}\text { Expert } \\
\text { elicitation }\end{array}$ & $\mathrm{N} / \mathrm{A}$ & $\begin{array}{l}0.02 \text { repair length } \\
\text { versus length of } \\
\text { inspection }\end{array}$ \\
\hline [25] & & & & $\begin{array}{l}827 \text { joints } \\
3200 \mathrm{~m}\end{array}$ & $\begin{array}{l}\text { 16/m (microscopic } \\
\text { cracks) }\end{array}$ \\
\hline [27] & & Cracks & $\begin{array}{l}\text { MPT and } \\
\text { EC } \\
\text { underwater }\end{array}$ & $\begin{array}{l}4000 \\
\text { inspection }\end{array}$ & $1 / 3$ per joint \\
\hline [28] & $\begin{array}{l}\text { Lower hull of } \\
\text { Conoco TLP }\end{array}$ & Defects & $\begin{array}{l}\text { MPT and } \\
\text { UT }\end{array}$ & $27000 \mathrm{~m}$ & $\begin{array}{l}0.01 \text { to } 0.014 \\
\text { ratio of defect length/ } \\
\text { total length of weld }\end{array}$ \\
\hline [29] & & & & & $10^{-4} / \mathrm{in}^{3}$ per volume \\
\hline [24] & Pressure vessel & & & & $\begin{array}{l}3.65 \text { microscopic per } \\
\text { pressure vessel }\end{array}$ \\
\hline [26] & $\begin{array}{l}\text { North sea } \\
\text { Structure } \\
\text { in splash zone }\end{array}$ & $\begin{array}{l}\text { Embedded } \\
\text { defects }\end{array}$ & $\begin{array}{l}\text { MPT and } \\
\text { UT }\end{array}$ & $\begin{array}{l}1000 \mathrm{~m} \\
\text { welds; } 18 \\
\text { joints }\end{array}$ & $0.7 / \mathrm{m}$ \\
\hline
\end{tabular}

\subsection{Defect size}

Defect size distribution is one of three key input variables to deterministic and probabilistic fracture mechanics assessment along with stress and material fracture toughness. These three inputs are known as the fracture mechanics triangle $[30,31]$. In engineering critical 
assessment (ECA), when reliable data over the whole range of possible values are not available, it is common to treat one or all of these parameters deterministically by assuming (an) upper/lower bound value(s). In reliability analyses, however, accurate and realistic defect size distributions is a vital input [32]. The choice of distribution type depends on two factors: 1. the nature of the physical phenomena modelled and 2: the goodness of fit of the data to distribution. A structure is likely to contain a large number of small defects and a much lower number of larger defects. When detected by NDT, a lower number of very small defects are found due to the poorer probability of detection for these defects; the probability of detection reduces as the sizes get smaller. Thus, lognormal and Weibull functions show suitable fit and are commonly used in the literature. When the effect of probability of detection is considered, an exponential distribution may be used.

The defect characteristics which have been included in the statistical analysis shown in Figure 3 are as follows:

- Defect height (2a) also called defect depth for surface-breaking defect (a).

- Defect length $(2 \mathrm{c})$

- Defect aspect ratio (taken as Length/Height)

In this research, the lognormal and Weibull distributions have been fitted to the data. Greater emphasis has been given to lognormal distribution for which there is some theoretical justification for its use [33].
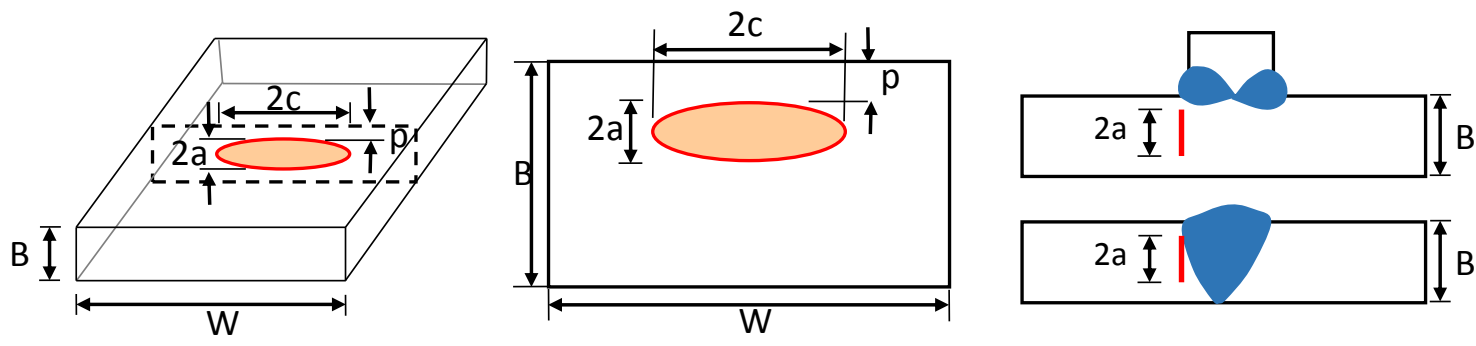

Figure 3 Dimensions of an idealised embedded defect

\subsubsection{Defect height or depth}

In many structures, the defect height/depth is the important dimension of the assumed flaw. For example, in a pressure vessel containing pressurized and possibly toxic or flammable substances, this can lead to severe consequences or an undercut surface crack in a bracing of an offshore jacket can lead to the failure of the member [34]. In ship structures, an embedded or surface crack can grow into a through thickness crack and further grow into a very long crack before causing a severe fracture [35-37], however occasionally a small crack can become unstable, as with the Kurdistan tanker failure [38]. 
Fabrication defect height data is not always available from NDT inspection of newbuilding ship hull structures for two main reasons. Firstly, traditionally NDT inspection has been practised as part of shipyards quality control scheme and not for fitness for service assessment. Defect height data is not commonly used after inspection. Defect length is used by quality control departments to calculate defect rate which is a measure of shipyard's quality. Secondly, some widely practised NDT methods such as Radiography Testing and Dye Penetrant testing will only provide the length of the defect, although a rough estimate of defect height can be obtained from Penetrant testing, when it is followed by grinding, or from Radiography Testing. In this research, datasets gathered from the shipyards only include defect length data. An extensive review of literature was carried out and the summary of distribution parameters is given in Table 6 below.

Townend fitted a Weibull distribution to lack of fusion and lack of penetration of welds from 1980 metres of node welds fabricated by manual metal arc welding in offshore structures [39]. Rogerson and Wang presented results on embedded defect height from a study of 1000 metres weld length in vertical and horizontal nodes of an offshore structure [26]. Comparisons between the models for the two investigations show that cumulative probabilities fall reasonably in the same range for depths up to $15 \mathrm{~mm}$ but there are marked variations for defects of depth larger than $15 \mathrm{~mm}$.

Kountouris et al. fitted Weibull and Lognormal functions to height and length of embedded defects resulting from Ultrasonic Testing of the lower hull of the Conoco TLP [23]. Selective parameters for planar defects in cruciforms and tee butts and plate butts extracted from [23] are shown in Table 6. They found that the welding process did not have a significant influence on embedded defects, however, the planar defect depths were found to be noticeably different for the two types of joints.

For surface-breaking defects, Becher and Hansen presented data from PWR vessels of defect length for slag inclusion and surface cracks [40]. The 233 surface cracks were not weld defects but were due to some kind of stress corrosion. They were detected by MPT and the crack dimension was measured as the depth of grinding. 


\begin{tabular}{|c|c|c|c|c|c|c|c|c|c|}
\hline \multirow[t]{2}{*}{ Investigator } & \multirow[t]{2}{*}{ NDT } & \multirow{2}{*}{$\begin{array}{l}\text { Joint } \\
\text { Type }\end{array}$} & \multirow{2}{*}{$\begin{array}{l}\text { Welding } \\
\text { Process }\end{array}$} & \multirow{2}{*}{ Flaw Type } & \multicolumn{2}{|c|}{ Lognormal } & \multicolumn{3}{|c|}{ Weibull } \\
\hline & & & & & $\mu$ & $\sigma$ & Shape & Scale & $\begin{array}{l}\text { Median } \\
(\mathrm{mm})\end{array}$ \\
\hline \multirow[t]{10}{*}[33,41]{} & \multirow[t]{7}{*}{ UT } & \multirow[t]{3}{*}{ Butt } & \multirow[t]{2}{*}{ SMAW } & LOF & 1.22 & 0.48 & 1.64 & 4.4 & 3.52 \\
\hline & & & & Crack & 1.93 & 0.64 & 1.56 & 9.57 & 7.57 \\
\hline & & & GMAW & LOF & 1.14 & 0.47 & 1.66 & 4.05 & 3.25 \\
\hline & & \multirow[t]{4}{*}{ Cruciform } & \multirow[t]{2}{*}{ SMAW } & LOF & 1.52 & 0.65 & 1.39 & 6.46 & 4.96 \\
\hline & & & & Crack & 2.17 & 0.67 & 1.67 & 12.2 & 9.80 \\
\hline & & & \multirow[t]{2}{*}{ GMAW } & LOF & 1.45 & 0.64 & 1.38 & 6.04 & 4.63 \\
\hline & & & & Crack & 2.11 & 0.70 & 1.57 & 11.67 & 9.24 \\
\hline & \multirow[t]{3}{*}{ MPT } & \multirow{3}{*}{$\begin{array}{l}\text { Butt and } \\
\text { Fillet }\end{array}$} & SMAW & Centre crack & 1.76 & 0.6 & 1.67 & 7.92 & 6.36 \\
\hline & & & GMAW & Centre crack & 2.015 & 0.73 & 1.6 & 10.66 & 8.48 \\
\hline & & & Pooled & Toe Crack & 0.346 & 0.15 & 1.31 & 1.62 & 1.22 \\
\hline [40] & MPT & Butt & MMA & Surface Crack & 0.16 & 1.15 & 2.06 & 0.95 & 1.4 \\
\hline$[26]$ & MPT and UT & & & Embedded Planar & 1.28 & 0.83 & 5.33 & 1.43 & 4.12 \\
\hline \multirow[t]{2}{*}{ [42] } & \multirow[t]{2}{*}{ UT } & \multirow[t]{2}{*}{ Butt } & \multirow[t]{2}{*}{ MMA } & LOF & 1.68 & 0.58 & 7.0 & 2.18 & 2.07 \\
\hline & & & & LOP & 1.9 & 0.46 & 8.13 & 2.76 & 2.64 \\
\hline [39] & UT & Butt & MMA & Pooled data & 1.76 & 0.49 & 7.2 & 2.43 & 6.19 \\
\hline [27] & MPT & & & Surface crack & 0.35 & 0.73 & 2.05 & 1.41 & 1.18 \\
\hline
\end{tabular}

Moan et al. presented data from 23 jacket offshore structures of surface breaking cracks [27]. Similar to [40], they were detected by MPT and the crack depth dimension was measured as the depth of grinding.

Kountouris and Baker fitted Weibull and Lognormal functions to depth and length of surfacebreaking defects resulting from MPT of weld length in the order of $50 \mathrm{~km}$ in an offshore structure [41]. They have shown a strong dependence of distribution parameters on the weld type, welding process and defect location within the joint. Selective parameters for planar defects in cruciform and tee butts, and plate butts extracted from [41] are shown in Table 6.

Among all the reviewed published work, defect size analyses reports from $[33,41]$ are the most comprehensive. The reports include information about joint type, defect type, defect location welding process and NDT method thus the extraction of defect size statistics are accurate and more reliable. Surface-breaking cracks reported by [40] and [27] are reasonably in the same size range but significantly different from [41] surface breaking cracks in weld centre. Toe cracks from [41] are consistent with [40] and [27]. This suggests that surface cracks at the centre of weld metal are bigger in height than the surface breaking cracks at the toe of the joint. In the absence of information about the location of the defect, it may be prudent to assume a centre crack. However, the stress at weld toe is higher than the weld centre line due to weld profile angle. When a weld is ground flush this stress concentration is reduced but then again, the depth of a centre line crack will be reduced as well, therefore it is not possible to make an accurate comparison of the severity of these two types of cracks at this stage and further crack growth analysis is required. Figure 4 shows a crack height 
cumulative density function from [41] and [33]. Apart from surface breaking cracks from SMAW process, there is a reasonable agreement among fitted functions.

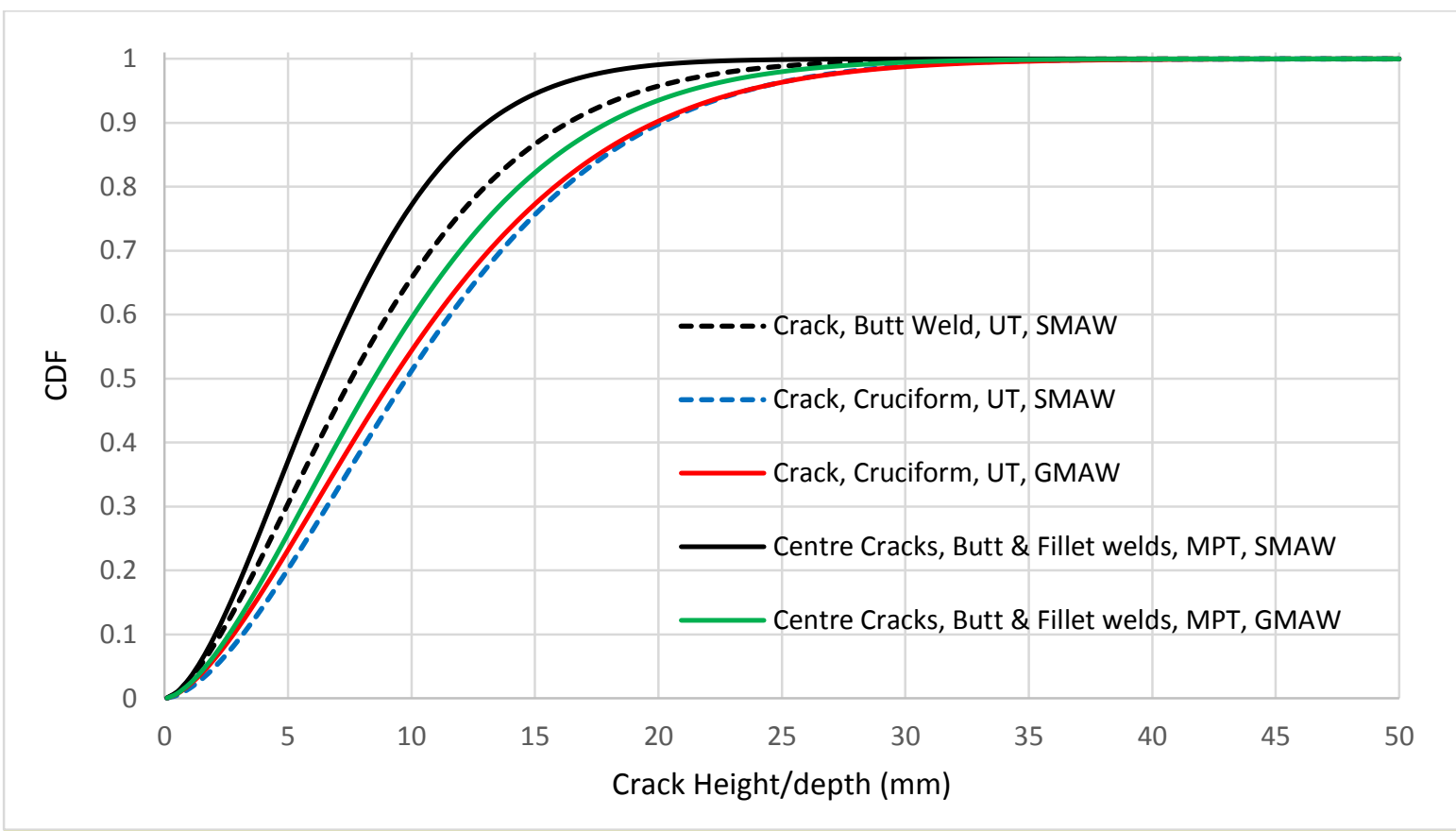

Figure 4 Crack Height/depth Cumulative density function from [33, 41]

\subsubsection{Defect length}

Kountouris and Baker show that incomplete penetration and crack-like defects typically have the highest mean lengths [33]. Mean values for the latter range from $260-414 \mathrm{~mm}$.

Surface-breaking cracks are found to have significantly smaller length than embedded defects. One explanation could be that surface breaking cracks larger than a certain length have a very high probability of being detected by visual inspection. i.e. median crack lengths are $30-37 \mathrm{~mm}$. The probability of detection with visual inspection of this range of crack length for easy access condition is $70-80 \%$ [22], and $90 \%$ probability of detection is achieved for cracks length above $160 \mathrm{~mm}$.

Burdekin reported distribution of lack of fusion and lack of penetration in tube to tube joints produced by manual metal arc welding of BS4360 50D steel and reported median defect length ranging between $280-330 \mathrm{~mm}$ [42].

Becher and Hansen reported solid inclusion length of ship steel grades produced by manual metal arc welding from Radiography testing and suggest median defect length of $8 \mathrm{~mm} \mathrm{[40].}$ Kihara fitted crack length data of shell plates to the Weibull distribution which gave the median value of $19.5 \mathrm{~mm}$ [43]. 
Table 7 Defect distributions distribution parameters from literature

\begin{tabular}{|c|c|c|c|c|c|c|c|c|c|}
\hline \multirow[b]{2}{*}{ Investigator } & \multirow[b]{2}{*}{ NDT } & \multirow[b]{2}{*}{ Joint Type } & \multirow[b]{2}{*}{ Process } & \multirow[b]{2}{*}{ Flaw Type } & \multicolumn{2}{|c|}{ Lognormal } & \multicolumn{3}{|c|}{ Weibull } \\
\hline & & & & & $\mu$ & $\sigma$ & Scale & Shape & $\begin{array}{c}\text { Median } \\
(\mathrm{mm})\end{array}$ \\
\hline \multirow{13}{*}{ [33] } & \multirow{13}{*}{ UT } & \multirow{5}{*}{ Butt } & \multirow{3}{*}{ SMAW } & LOF & 4.5 & 1.24 & 164.7 & 0.93 & 111.05 \\
\hline & & & & Crack & 5.08 & 1.17 & 270.8 & 1.12 & 195.22 \\
\hline & & & & Slag inc. & 4.63 & 1.14 & 179.17 & 0.97 & 122.79 \\
\hline & & & \multirow{2}{*}{ GMAW } & Slag inc. & 3.77 & 1.72 & 163.4 & 0.94 & 110.64 \\
\hline & & & & LOF & 1.66 & 2.01 & 233.9 & 0.84 & 151.19 \\
\hline & & \multirow{8}{*}{ Cruciform } & \multirow{4}{*}{ SMAW } & LOF & 5.04 & 1.09 & 265.3 & 0.87 & 174.09 \\
\hline & & & & Crack & 5.06 & 1.11 & 272.31 & 0.98 & 187.34 \\
\hline & & & & Slag inc. & 4.63 & 1.14 & 223.45 & 0.97 & 153.14 \\
\hline & & & & Porosity & 5.04 & 1.18 & 275.16 & 0.93 & 185.54 \\
\hline & & & \multirow{4}{*}{ GMAW } & LOF & 4.98 & 1.27 & 276.12 & 0.80 & 174.63 \\
\hline & & & & Crack & 1.57 & 3.42 & 334.2 & 0.75 & 205 \\
\hline & & & & Slag inc. & 5.02 & 1.77 & 280.6 & 0.82 & 179.46 \\
\hline & & & & Porosity & 1.33 & 2.66 & 174.8 & 0.93 & 117.87 \\
\hline \multirow{2}{*}{ [41] } & \multirow{2}{*}{ MPT } & \multirow{2}{*}{ Butt and Fillet } & SMAW & Centre crack & 3.49 & 0.95 & 52.18 & 1.04 & 36.68 \\
\hline & & & GMAW & Centre crack & 3.31 & 0.65 & 36.5 & 2.1 & 30.65 \\
\hline \multirow{2}{*}{ [42] } & \multirow{2}{*}{ UT } & \multirow{2}{*}{ Butt } & \multirow{2}{*}{ MMA } & LOF & 0.94 & 0.61 & 341 & 2.14 & 287.32 \\
\hline & & & & LOP & 1.11 & 0.36 & 361 & 3.65 & 326.51 \\
\hline [40] & RT & Butt & MMA & Slag inc. & 1.97 & 0.81 & 10.87 & 1.2 & 8.01 \\
\hline [43] & & Shell plates & & Crack & 2.97 & 0.06 & 20.25 & 10.1 & 19.5 \\
\hline
\end{tabular}

\subsubsection{Defect aspect ratio}

Reliable data on the aspect ratio defined as the ratio of defect length to defect depth are virtually non-existent. Kountouris and Baker have fitted Lognormal and Weibull distributions to surface-breaking defects and embedded defects in an offshore structure [41]. They showed that the distribution parameters are highly dependent on defect type, weld type, welding process and defect location within the joint. Table 8 shows the lognormal and Weibull parameters, obtained for a sample of cases in cruciform and tee butt welds.

Table 8 Defect aspect ratio distribution parameters from $[33,41]$

\begin{tabular}{|c|c|c|c|c|c|c|c|c|c|}
\hline \multirow[t]{2}{*}{ Investigator } & \multirow[t]{2}{*}{ NDT } & \multirow[t]{2}{*}{ Joint } & \multirow[t]{2}{*}{ Process } & \multirow[t]{2}{*}{ Flaw Type } & \multicolumn{2}{|c|}{ Lognormal } & \multicolumn{3}{|c|}{ Weibull } \\
\hline & & & & & $\mu$ & $\sigma$ & Scale & Shape & Median \\
\hline \multirow[t]{11}{*}[33,41]{} & \multirow[t]{11}{*}{ UT } & \multirow[t]{5}{*}{ Butt } & \multirow[t]{3}{*}{ SMAW } & LOF & 3.29 & 1.28 & 49.55 & 0.90 & 33.03 \\
\hline & & & & Crack & 3.15 & 1.26 & 42.97 & 0.88 & 28.33 \\
\hline & & & & Slag inc. & 3.67 & 1.20 & 70.92 & 0.89 & 46.98 \\
\hline & & & \multirow[t]{2}{*}{ GMAW } & Slag inc. & 3.58 & 1.21 & 65.27 & 0.87 & 42.83 \\
\hline & & & & LOF & 3.65 & 1.41 & 77.70 & 0.77 & 48.27 \\
\hline & & \multirow[t]{6}{*}{ Cruciform } & \multirow[t]{3}{*}{ SMAW } & LOF & 3.28 & 1.28 & 61.40 & 0.81 & 39.05 \\
\hline & & & & Crack & 3.15 & 1.26 & 32.40 & 0.87 & 21.26 \\
\hline & & & & Slag inc. & 3.66 & 1.20 & 84.00 & 0.96 & 57.34 \\
\hline & & & \multirow[t]{3}{*}{ GMAW } & LOF & 3.53 & 1.39 & 68.57 & 0.72 & 41.22 \\
\hline & & & & Crack & 3.02 & 1.35 & 40.00 & 0.76 & 24.70 \\
\hline & & & & Slag inc. & 4.07 & 1.24 & 109.7 & 0.82 & 70.16 \\
\hline
\end{tabular}




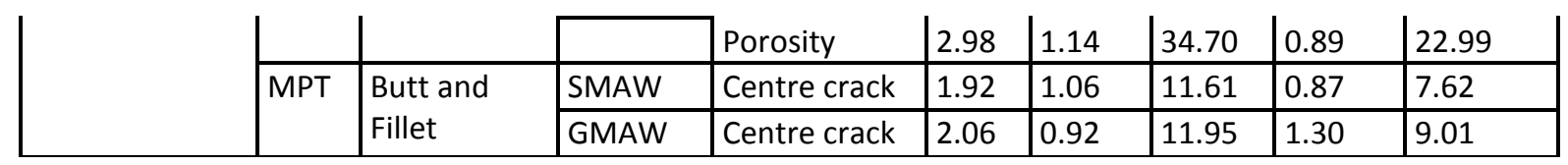

\section{Analysis}

Defect data was acquired using the data collected during newbuilding ship manufacturing quality control programmes, in which, conventional NDT methods are commonly used. The authors have made the research data available via this journal.

In a data Quality Control (QC) of such welds are predominantly reliant on $100 \%$ visual inspection of finished welds complimented by partial NDT inspection on a sampling basis. Since the welds are already visually inspected, volumetric NDT methods capable of detecting subsurface and embedded defects are the main selected methods. Among volumetric NDT methods, RT and UT are the most commonly used methods [3]. The main limitation of RT is its lack of reliability in detecting planar defects. The UT method on the other hand can detect planar flaws with high reliability but is limited to thicknesses above $8 \mathrm{~mm}$. The thickness limitation of UT makes RT the most common method used in the manufacturing of passenger ships, where the structure is made of multiple decks.

\subsection{Flaw frequency analysis}

The studied ships are built with three welding process: SAW, HLAW and FCAW. The breakdown of executed welding processes for ship \#2 (built 2013) and ship \#3 (built 2011) was not available; however, such data was available from ship \#1 which was built in the same ship yard and with comparatively similar basic dimensions (Table 9). The dimensions of ship \#3 were not available in the dataset. Figure 7 shows the breakdown of welding processes within the hull areas.

Table 9 Comparison between basic characteristics of ship\#1 and Ship \#2

\begin{tabular}{|l|l|l|}
\hline Characteristic & Welding data ship \#1 & NDT Data ship \#2 \\
\hline Length & $305.60 \mathrm{~m}$ & $330 \mathrm{~m}$ \\
\hline Beam & $37.2 \mathrm{~m}$ & $44 \mathrm{~m}$ \\
\hline Height & - & $70.67 \mathrm{~m}$ \\
\hline Number of Decks & 15 & 15 \\
\hline Draught & $8.20 \mathrm{~m}$ & $8.30 \mathrm{~m}$ \\
\hline
\end{tabular}

As Figure 5 and Figure 6 show, over $63 \%$ of weldments are made with HLAW, but, only $7 \%$ of the checkpoints are selected from HLAW weldments. $5 \%$ of welds are made with SAW process. It is evident from Figure 7 that unless process limitations were prevented, HLAW was used for joining deck panels which make up $85 \%$ of all the welding, otherwise SAW was 
employed. $2 \%$ of NDT checkpoints are from joints made with SAW. The FCAW makes up about $30 \%$ of welds, but comprise the majority of NDT checkpoints: $91 \%$ of the total checkpoints (Figure 6). FCAW process is used in joints where SAW and HLAW cannot be selected due to access restrictions; i.e. the connection between grand blocks.

These joints are believed to be more prone to defect formation; particularly crack type defects can be caused by higher joint restraint and welding conditions; e.g. outdoor workshop [10, $44,45]$.

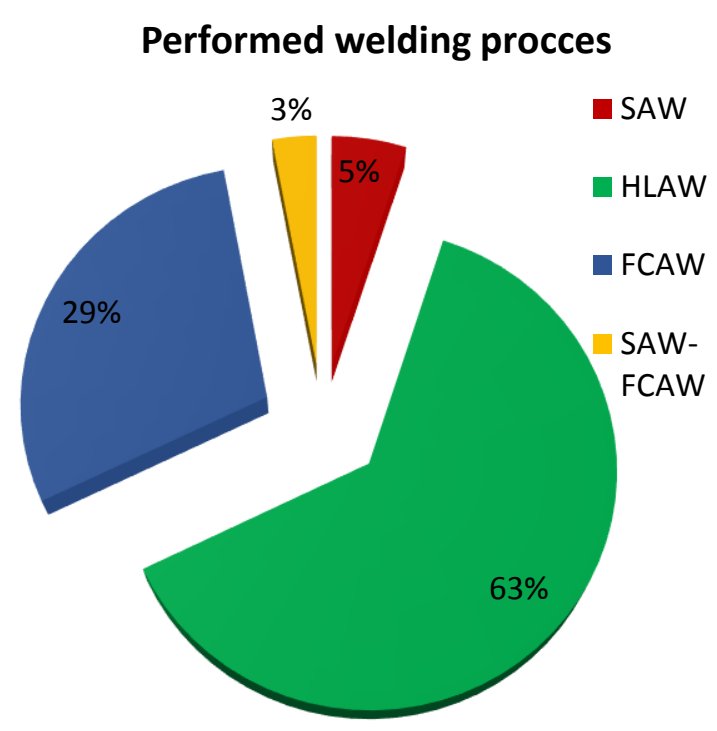

Figure 5 Performed welding break down with respect to process from ship \#1

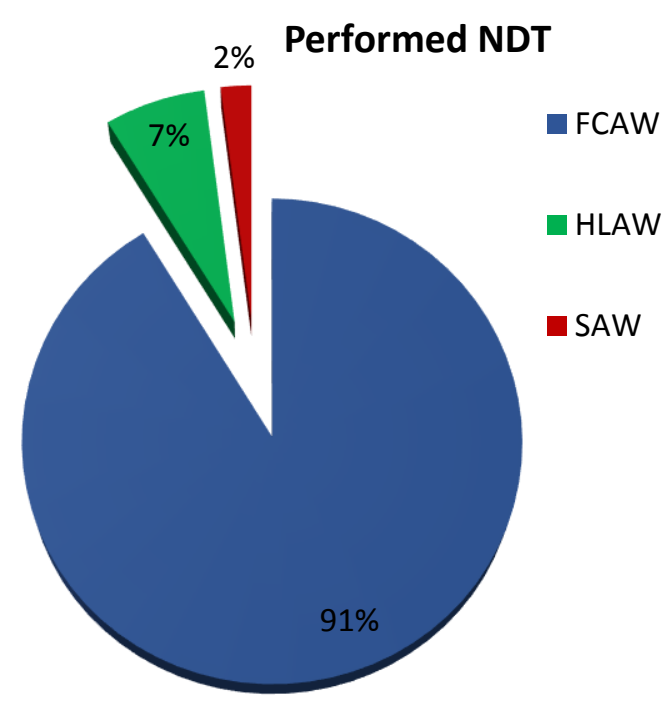

Figure 6 Performed NDT break down with respect to process from ship \#1 


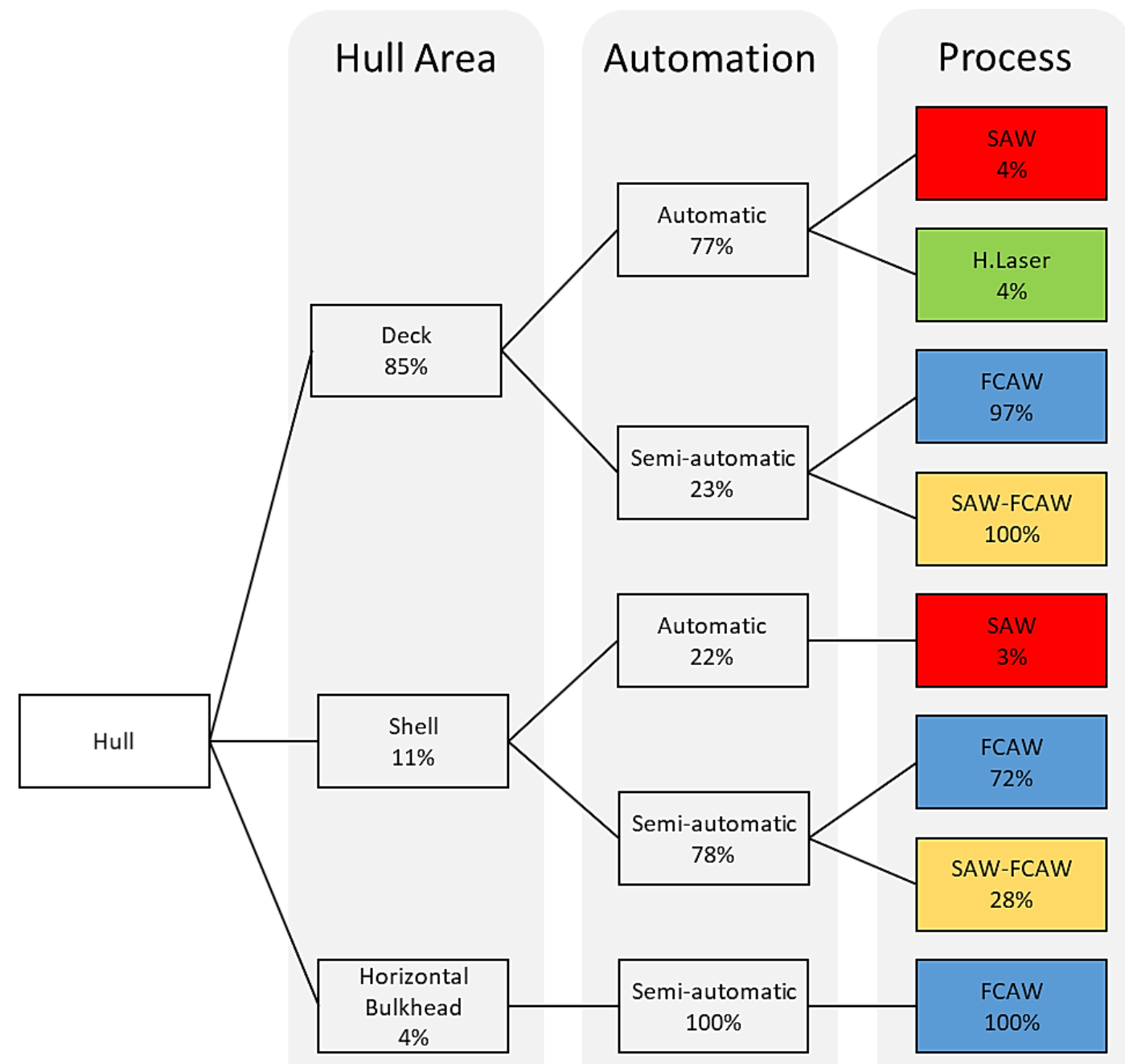

Figure 7 Welding break down with respect to hull area, Level of Automation and process from ship \#1

NDT statistics of ships \# 2 and \# 3 are given in Table 10. It can be observed that process breakdown of ship \# 2 is very similar to ship \#1. This can be explained by similarity of the structures. In ship \# 3, 97\% of the NDT tests are performed on FCAW welds and 2 tests were performed on HLAW weldments. The results from three ships show that the focus of inspection is on FCAW joints and inspection of HLAW and SAW welds is limited.

\begin{tabular}{|c|c|c|c|c|c|c|c|c|c|c|c|}
\hline \multirow{2}{*}{\multicolumn{2}{|c|}{ NDT }} & \multicolumn{5}{|l|}{ Ship \# 2} & \multicolumn{5}{|c|}{ Ship \# 3} \\
\hline & & FCAW & SAW & HLW & Total & \begin{tabular}{|l|}
$\%$ \\
(NDT)
\end{tabular} & FCAW & SAW & HLW & Total & $\begin{array}{l}\% \\
\text { (NDT) }\end{array}$ \\
\hline RT & \multirow{5}{*}{$\begin{array}{l}\text { Number } \\
\text { of tests }\end{array}$} & 5962 & 143 & 471 & 6576 & 92.6 & 2557 & 79 & 2 & 2638 & 87 \\
\hline UT & & 235 & 1 & 7 & 243 & 3.4 & 380 & 4 & 0 & 384 & 13 \\
\hline MPT & & 268 & 0 & 0 & 268 & 3.8 & 0 & 0 & 0 & 0 & \\
\hline DPT & & 12 & 0 & 0 & 12 & 0.2 & 0 & 0 & 0 & 0 & \\
\hline Total & & 6477 & 144 & 478 & 7099 & & 2937 & 83 & 2 & 3022 & \\
\hline \multicolumn{2}{|c|}{ Length (m) } & 3108.96 & 69.12 & 229.44 & 3407.52 & & 1409.76 & 39.84 & 0.96 & 1450.56 & \\
\hline \multicolumn{2}{|c|}{ \% (Process) } & 91.2 & 2.0 & 6.7 & & & 97.2 & 2.7 & 0.07 & & \\
\hline
\end{tabular}


Defect percentage breakdown for ship \#2 and \#3 is given in Table 11, Figure 8 and Figure 9. In both ships, cavities are the most common defect type found in all processes. Cavities are not generally considered very harmful unless they are extensive in relation to weld crosssection [11]. Cracks are the least common defects found in all processes. In ship \#2, Lack of fusion (LOF) and lack of penetration (LOP) are also common in SAW and HLAW processes. LOP and LOF are considered as planar defects and can significantly reduce the fatigue life of the joints, therefore FCAW welds may show superior fatigue performance. Around $90 \%$ of the NDTs are performed using Radiography Testing. As pointed out earlier, RT is not a reliable method for detection of planar defects but very reliable for detecting nonplanar defects, therefore, higher percentage of cavities and solid inclusions compared to cracks, lack of fusion and lack of penetration could be due to the effectiveness of the NDT method rather that the process itself; if i.e. UT was the dominant method the breakdown of the defects could have been very different and significantly more planar defects could have been found (see Table 4 for NDT capabilities comparisons).

Table 11 Detected defects breakdown

\begin{tabular}{|l|l|l|l|l|l|l|l|l|l|l|l|l|l|l|}
\hline \multirow{2}{*}{ Defects } & \multicolumn{3}{|c|}{ Ship \#2 } & \multicolumn{3}{c|}{ Ship \#3 } & \multicolumn{3}{c|}{ Ship \#2 } & \multicolumn{3}{c|}{ Ship \#3 } \\
\cline { 2 - 15 } & FCAW & SAW & HLAW & FCAW & SAW & HLAW & FCAW & SAW & HLAW & FCAW & SAW & HLAW \\
\hline Cracks & 210 & 1 & 2 & 60 & 4 & 0 & $9 \%$ & $3 \%$ & $4 \%$ & $10 \%$ & $14 \%$ & $0 \%$ \\
\hline Cavities & 996 & 14 & 23 & 336 & 12 & 0 & $44 \%$ & $35 \%$ & $49 \%$ & $58 \%$ & $41 \%$ & $0 \%$ \\
\hline Solid Inclusion & 833 & 11 & 3 & 141 & 10 & 0 & $37 \%$ & $28 \%$ & $6 \%$ & $25 \%$ & $34 \%$ & $0 \%$ \\
\hline LOP/LOF & 235 & 14 & 19 & 38 & 3 & 0 & $10 \%$ & $35 \%$ & $40 \%$ & $7 \%$ & $10 \%$ & $0 \%$ \\
\hline Total & 2274 & 40 & 47 & 575 & 29 & 0 & & & & & & \\
\hline
\end{tabular}

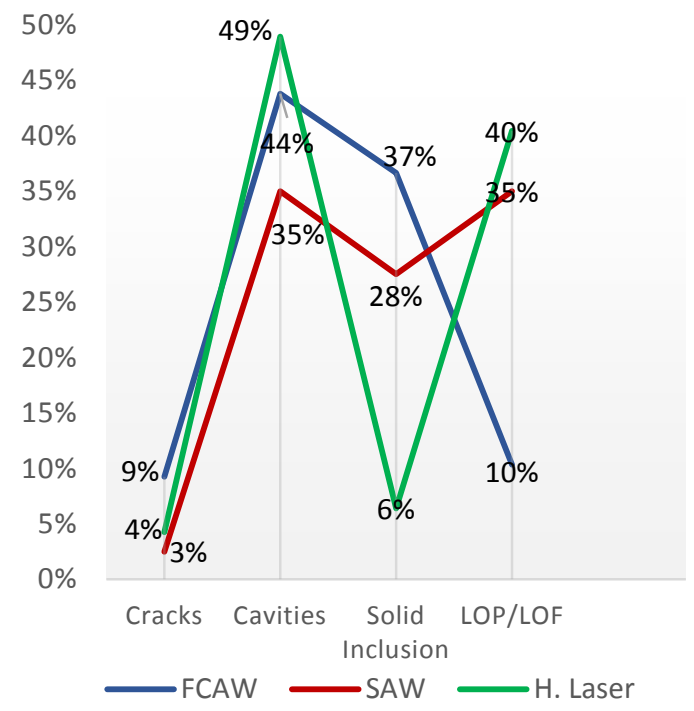

Figure 8 Ship \#2 defect percentage break down

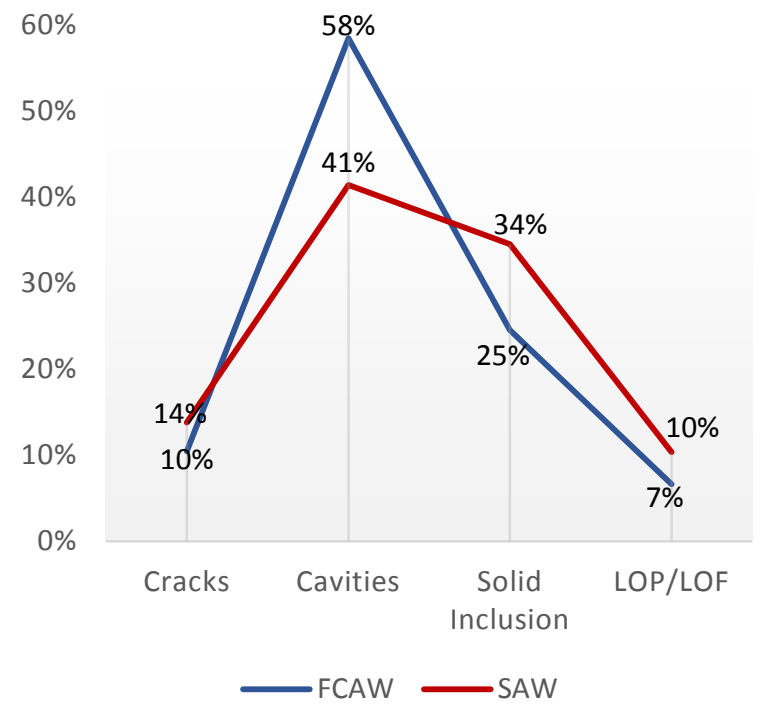

Figure 9 Ship \#3 defect percentage break down 


\subsection{Defect rates}

The availability of details varies among data sets. Data from Ship \#1 only includes repair lengths, inspected lengths and the relevant NDT method; however, no information is available regarding defect types and sizes. Ship \#2 data is the most comprehensive dataset and includes type, location, welding process, NDT method, and length of detected defects. Data from ship \#3 contains almost the same level of detail information, however, the number of the checkpoints are less than $50 \%$ of those for ship \#2. Defect rates of these three vessels, the sample sizes and the NDT methods are given in Table 12 to Table 14.

Figure 10 and Figure 11 show defect rates for the three welding processes. HLAW process creates significantly lower defect rates, around three times lower than the other two welding processes. This can imply that less inspections may be allowed for HLAW. From a quality control point of view, there are two methods practiced in the shipyards for estimating defect rates: The first method adopts a binary approach in which the number of detected defects is divided by the total number of inspections $(n / N)$. Similarly, the number of defects can be divided by the length of inspections to give the number of defects per meter length $(\mathrm{n} / \mathrm{m})$. The second method divides the total length of defects by the total length of examined welds. The latter is more meaningful for cavity defects which are normally recorded as the length of affected welds i.e. elongated porosity. In structures consisting of large length of weld lines the number of defects per meter is a better representative of defect frequency and has a direct relation with reliability [46]. Figure 10 and Figure 11 show the defect per meter rates.

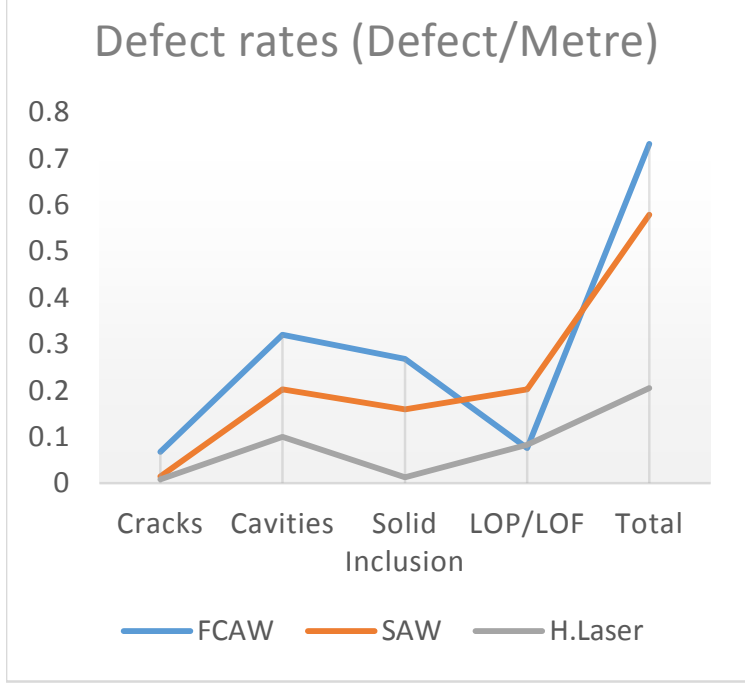

Figure 10 Ship \#2 defect rates

\section{Defect rates (Defect/Metre)}

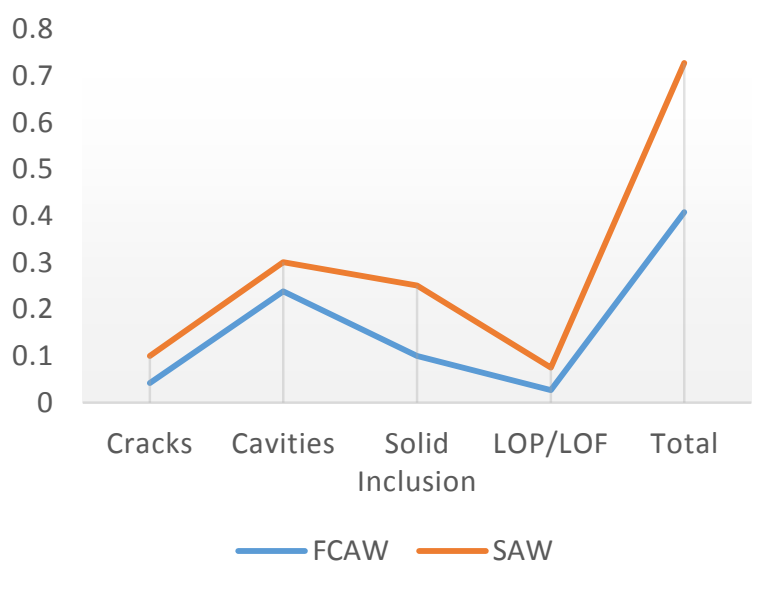

Figure 11 Ship \#3 defect rates

The defect rates vary significantly among the three ships. Data for defect rate of ship \#1 only gives total repair length divided by inspection length. The repair length includes multiple defects occurring, therefore, it is not an accurate representative occurrence frequency of defects. For comparison purposes, defect rates for ships \#2 and \#3 were also calculated as 
length of unacceptable tests divided by acceptable and unacceptable tests and are given in Table 12. Overall defect rates of ship \#2 and ship \#3 are very close and are around 0.23 , but defect rate for ship \#1 is almost half of the other two. This could be due to the employed NDT method; notice that majority of inspections for ship \#1 is done using UT but, in ships \#2 and $\# 3$, RT is used for about $90 \%$ of inspections. Opposite to RT, UT is generally considered to be a superior NDT method in detecting planar defects, therefore lower defects rates of ship \#1 could be explained by using UT in ship \#1 whose defect dataset may have been dominated by planar defects; As can be understood from Table 13 and Table 14 the planar defect (crack + LOP/LOF) rates for ships \#2 and \#3 are, generally, around 0.14 .

Table 12 Ship \#1 recorded defect rates vs. Ship \#2 \& ship \#3

\begin{tabular}{|l|l|l|l|l|}
\hline Dataset & NDT Type & Sample size & Defect rate \\
\hline Ship \#1 & RT 22\% and UT 78\% & $7200(\mathrm{~m})$ & 0.13 & Repair Length / Inspection length \\
\hline Ship \#2 & $\begin{array}{l}\text { RT 92*, UT 3.4\%, MPT 3.8\% } \\
\text { and DPT 0.2\% }\end{array}$ & $3550(\mathrm{~m})$ & 0.26 & $\begin{array}{l}\text { Length of unacceptable test/ (Acceptable + } \\
\text { Unacceptable) }\end{array}$ \\
\hline Ship \#3 & RT 87\% and UT 13\% & $1500(\mathrm{~m})$ & 0.21 & $\begin{array}{l}\text { Length of unacceptable tests/ (Acceptable } \\
\text { + Unacceptable) }\end{array}$ \\
\hline
\end{tabular}

Detailed defect rates of ship \#2 and ship \#3 show that there is a significant variation among the defect types which can be explained by the choice of NDT method and also between two ships. Another important factor is the statistical confidence: notice that in SAW and HLAW the sample sizes are significantly smaller than those from FCAW.

Table 13 Ship \#2 recorded defect rates

\begin{tabular}{|l|l|l|l|l|l|l|l|l|l|}
\hline \multirow{2}{*}{ Defects } & \multicolumn{9}{|l|}{ FCAW } \\
\cline { 2 - 12 } & Number & $\begin{array}{l}\text { rate } \\
(\mathrm{n} / \mathrm{N})\end{array}$ & $\begin{array}{l}\text { rate } \\
(\mathrm{n} / \mathrm{m})\end{array}$ & Number & $\begin{array}{l}\text { rate } \\
(\mathrm{n} / \mathrm{N})\end{array}$ & $\begin{array}{l}\text { rate } \\
(\mathrm{n} / \mathrm{m})\end{array}$ & Number & $\begin{array}{l}\text { rate } \\
(\mathrm{n} / \mathrm{N})\end{array}$ & $\begin{array}{l}\text { rate } \\
(\mathrm{n} / \mathrm{m})\end{array}$ \\
\hline Cracks & 210 & 0.032 & 0.067 & 1 & 0.007 & 0.014 & 2 & 0.004 & 0.009 \\
\hline Cavities & 996 & 0.154 & 0.320 & 14 & 0.097 & 0.202 & 23 & 0.048 & 0.100 \\
\hline Solid Inclusion & 833 & 0.128 & 0.268 & 11 & 0.076 & 0.159 & 3 & 0.006 & 0.013 \\
\hline LOP/LOF & 235 & 0.036 & 0.075 & 14 & 0.097 & 0.202 & 19 & 0.04 & 0.083 \\
\hline Total & 2274 & 0.351 & 0.731 & 40 & 0.278 & 0.579 & 47 & 0.098 & 0.205 \\
\hline
\end{tabular}

Table 14 Ship \#3 recorded defect rates

\begin{tabular}{|l|l|l|l|l|l|l|}
\hline \multirow{2}{*}{ Defects } & FCAW & \multicolumn{3}{l|}{ SAW } \\
\cline { 2 - 7 } & Number & rate $(\mathrm{n} / \mathrm{N})$ & rate $(\mathrm{n} / \mathrm{m})$ & Number & rate $(\mathrm{n} / \mathrm{N})$ & rate $(\mathrm{n} / \mathrm{m})$ \\
\hline Cracks & 60 & 0.020 & 0.042 & 4 & 0.048 & 0.100 \\
\hline Cavities & 336 & 0.114 & 0.238 & 12 & 0.144 & 0.301 \\
\hline Solid Inclusion & 141 & 0.048 & 0.100 & 10 & 0.120 & 0.251 \\
\hline LOP/LOF & 38 & 0.013 & 0.027 & 3 & 0.036 & 0.075 \\
\hline Total & 575 & 0.196 & 0.408 & 29 & 0.349 & 0.728 \\
\hline
\end{tabular}




\subsection{Defect length}

The defect length data for different defect types were fitted to candidate distributions which are known to show appropriate fit. Weibull, lognormal and General Extreme Value (GEV) distributions showed the best fits. Goodness-of-fit were judged based on corresponding loglikelihood; the higher the log-likelihood, the better the fit. The estimated distribution parameters and the log-likelihood values are summarised in Table 15. The probability density distributions are depicted in Figure 12 to Figure 19 and cumulative probability distributions (CDF) are plotted in Figure 20 to Figure 27.

Generally, all three distributions show relatively comparable results with GEV distribution showing better fits since it is defined with three parameters as opposed to the Weibull and lognormal distributions defined with two parameters only. LOP/LOF data for ship \#2 and solid inclusion data for both ships show prominent second mode as can be seen in Figure 14, Figure 18 and Figure 19. This could be an indication that the defects are caused by two different mechanisms: one creates bigger defect lengths than the other. Therefore, the data was fitted to a bi-modal Weibull distribution, as well. The bi-modal distribution shows clearly a better fit than the rest for LOP/LOF and solid inclusion data of ship \#2 by increasing log-likelihood by 51 and 61, respectively. This can be visually observed in Figure 22 and Figure 26. However, the goodness of fit for solid inclusion data of ship \#3 is only marginally increased.

Table 15 Defect data distribution fitting results for ship \#2 \& \#3

\begin{tabular}{|c|c|c|c|c|c|c|c|c|c|}
\hline \multirow[t]{2}{*}{ Distribution } & \multirow[t]{2}{*}{ Parameters } & \multicolumn{4}{|c|}{ Ship \#2 } & \multicolumn{4}{|c|}{ Ship \#3 } \\
\hline & & Cracks & $\begin{array}{l}\text { LOP } \\
/ \text { LOF }\end{array}$ & Cavity & $\begin{array}{l}\text { Solid } \\
\text { inclusion }\end{array}$ & Cracks & $\begin{array}{l}\text { LOP } \\
\text { /LOF }\end{array}$ & Cavity & \begin{tabular}{|l|} 
Solid \\
inclusion
\end{tabular} \\
\hline \multirow[t]{3}{*}{ Weibull } & Scale & 29.3 & 160.73 & 73.46 & 175.82 & 35.3 & 91.1 & 59.6 & 81.73 \\
\hline & Shape & 1.73 & 0.87 & 0.98 & 1.07 & 0.97 & 0.87 & 0.92 & 0.98 \\
\hline & Loglikelihood & -258 & -681 & -2207 & -1827 & -256 & -139 & -1513 & -681 \\
\hline \multirow[t]{3}{*}{ lognormal } & $\mathrm{Mu}$ & 3.1 & 4.46 & 3.81 & 4.66 & 3.12 & 3.89 & 3.562 & 3.89 \\
\hline & Std & 0.57 & 1.2 & 0.92 & 1 & 0.8 & 1.25 & 1 & 1 \\
\hline & Loglikelihood & -252 & -673 & -2139 & -1812 & -242 & -138 & -1469 & -668 \\
\hline \multirow[t]{4}{*}{ GEV } & shape & 0.1 & 1.01 & 0.7 & 0.8 & 0.63 & 1.056 & 0.73 & 0.68 \\
\hline & scale & 10.06 & 49.2 & 22.53 & 58.5 & 9.99 & 31 & 19.3 & 28.6 \\
\hline & location & 19 & 49 & 30 & 67.2 & 15.82 & 27.42 & 22.98 & 32.95 \\
\hline & loglikelihood & -252 & -670 & -2118 & -1814 & -237 & -139 & -1461 & -669 \\
\hline \multirow[t]{4}{*}{ Bi-modal } & shape 1 & & 2.074 & & 2.15 & & & & 1.5 \\
\hline & scale 1 & & 51.51 & & 68.42 & & & & 52.8 \\
\hline & shape 2 & & 6.7 & & 3.74 & & & & 3.5 \\
\hline & scale 2 & & 468.57 & & 391.96 & & & & 323.1 \\
\hline
\end{tabular}




\begin{tabular}{|l|l|l|l|l|l|l|l|l|l|}
\hline & $p$ & & 0.665 & & 0.623 & & & & 0.85 \\
\cline { 2 - 10 } & loglikelihood & & -619 & & -1751 & & & & -664 \\
\hline Sample size & & 65 & 111 & 416 & 298 & 57 & 26 & 295 & 126 \\
\hline Median & & 22.2 & 86.5 & 45.1 & 105.6 & 22.6 & 48.9 & 35.1 & 48.9 \\
\hline $\begin{array}{l}90^{\text {th }} \\
\text { percentile } \\
\text { value }\end{array}$ & & 46.1 & 402.6 & 146.8 & 380.5 & 63.1 & 242.7 & 126.6 & 176.2 \\
\hline
\end{tabular}




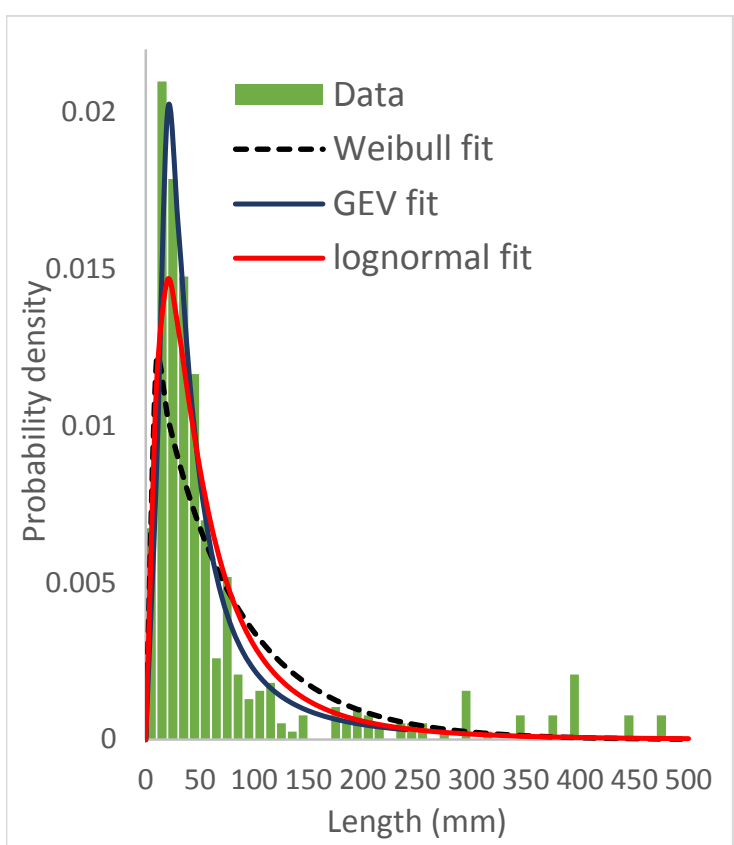

Figure 12 Ship \#2 Cavity length PDF

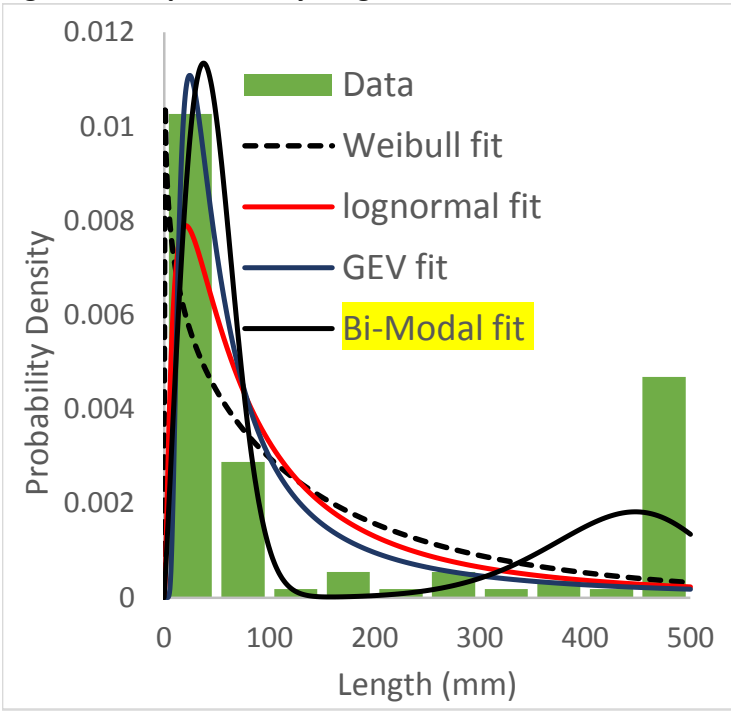

Figure 14 Ship \#2 LOP/LOF PDF

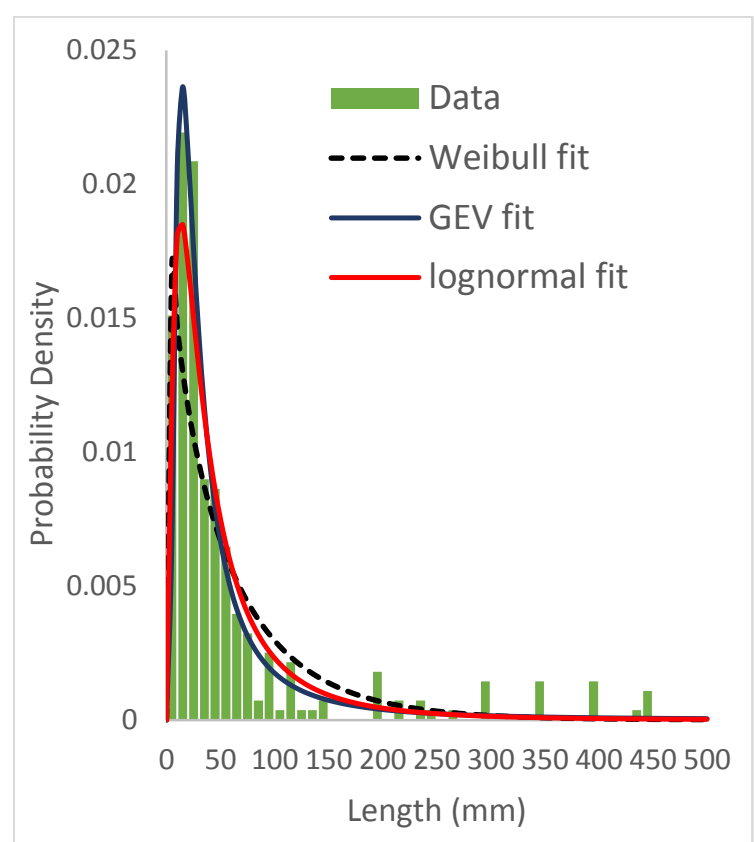

Figure 13 Ship \#3 Cavity length PDF

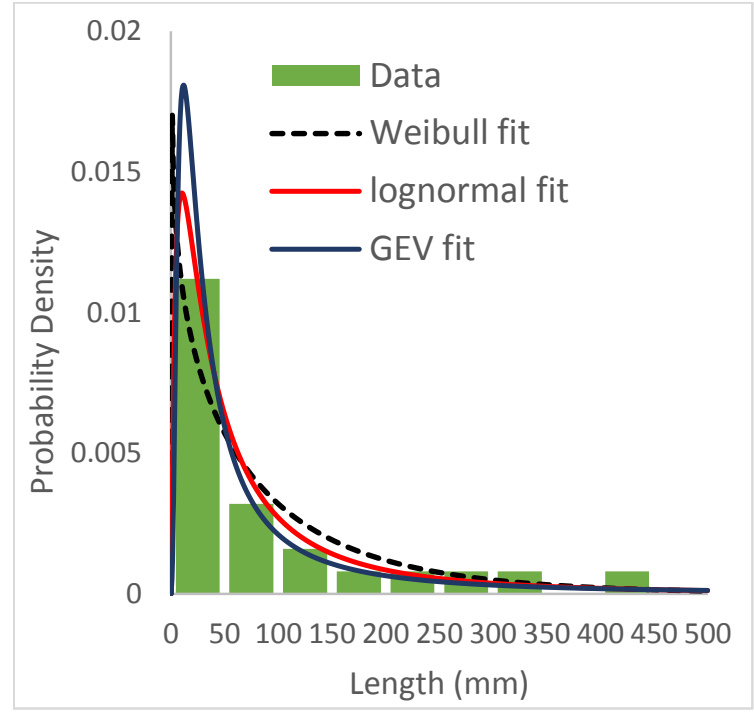

Figure 15 Ship \#3 LOP/LOF PDF 


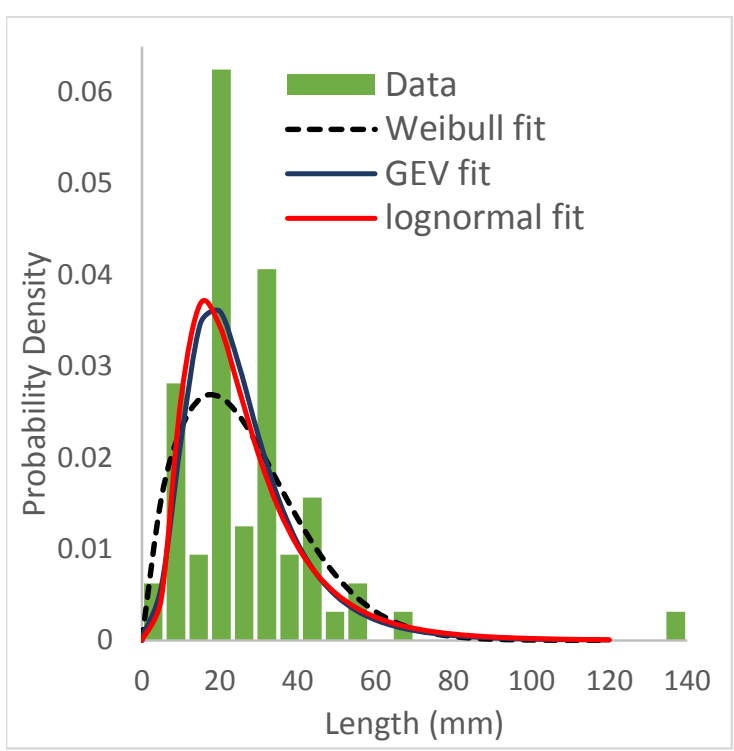

Figure 16 Ship \#2 Crack length PDF

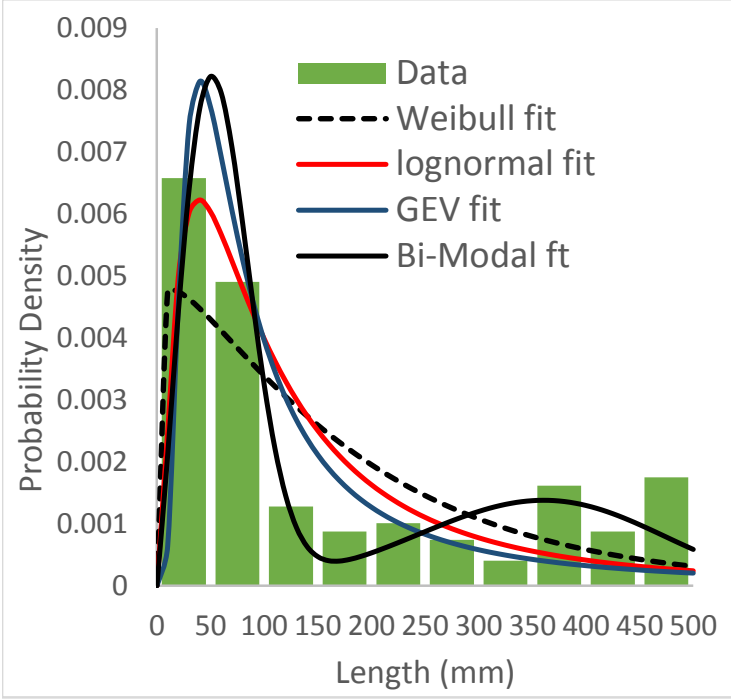

Figure 18 Ship \#2 Solid inclusion length PDF

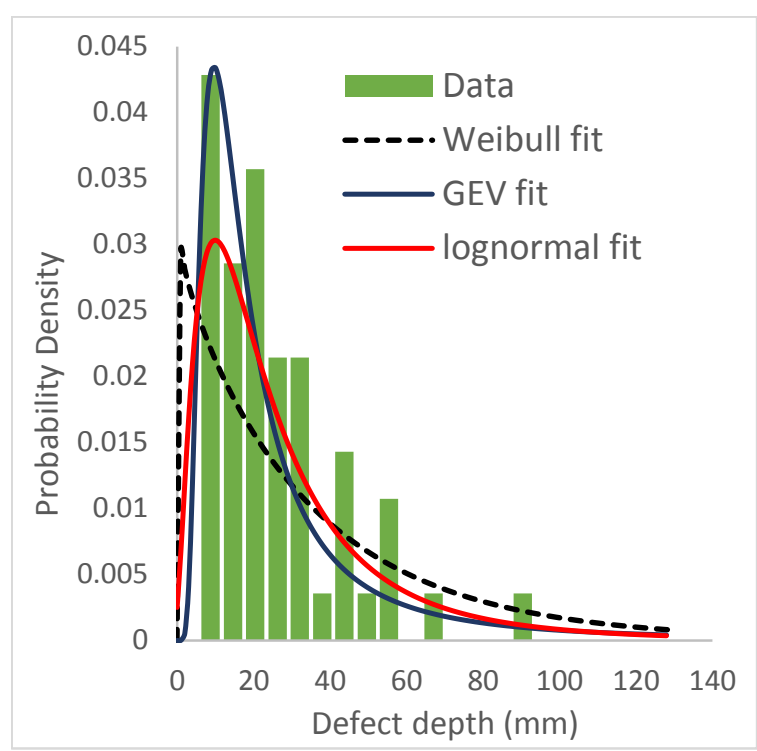

Figure 17 Ship \#3 Crack length PDF

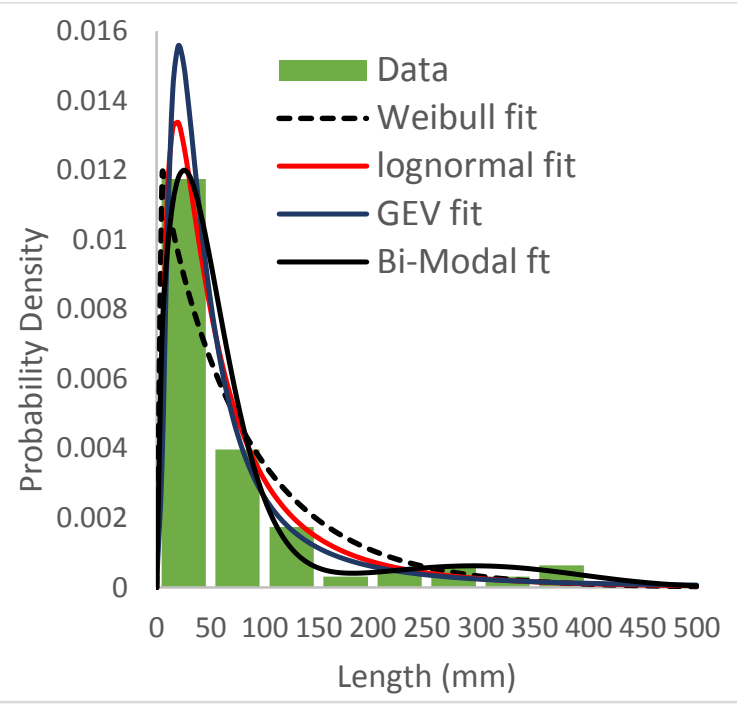

Figure 19 Ship \#3 Solid inclusion length PDF 


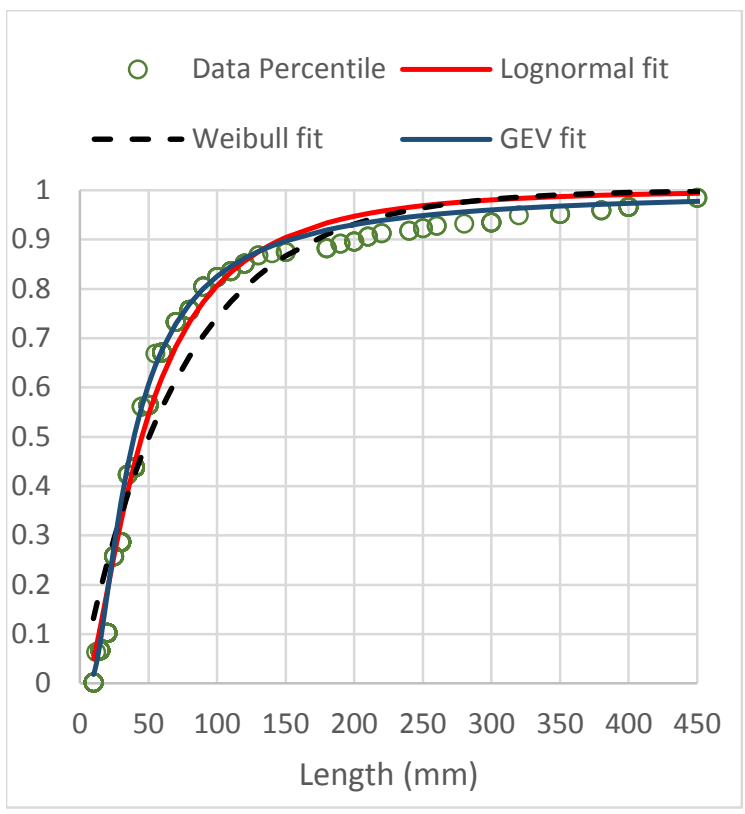

Figure 20 Ship \#2 Cavity length CDF

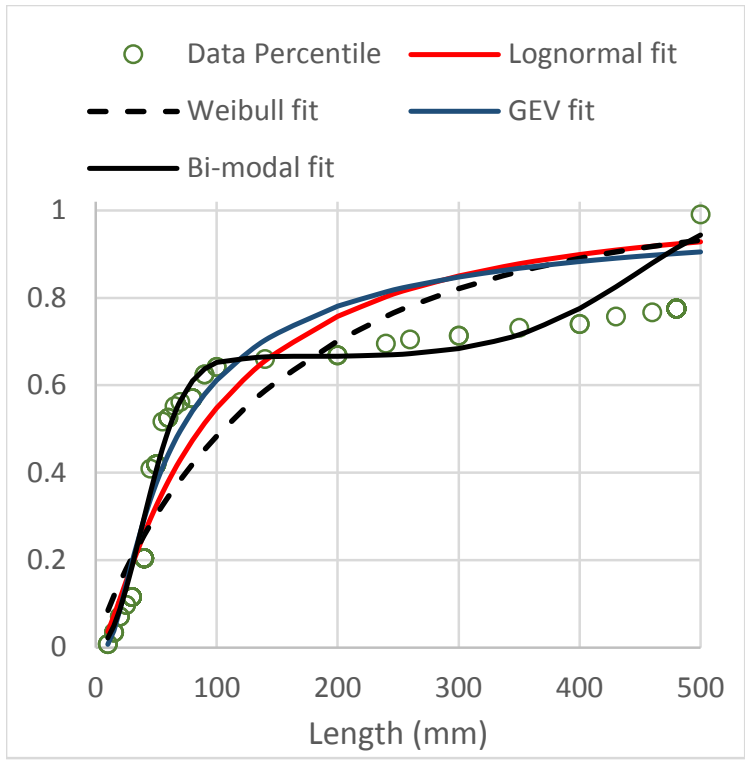

Figure 22 Ship \#2 LOP/LOF CDF

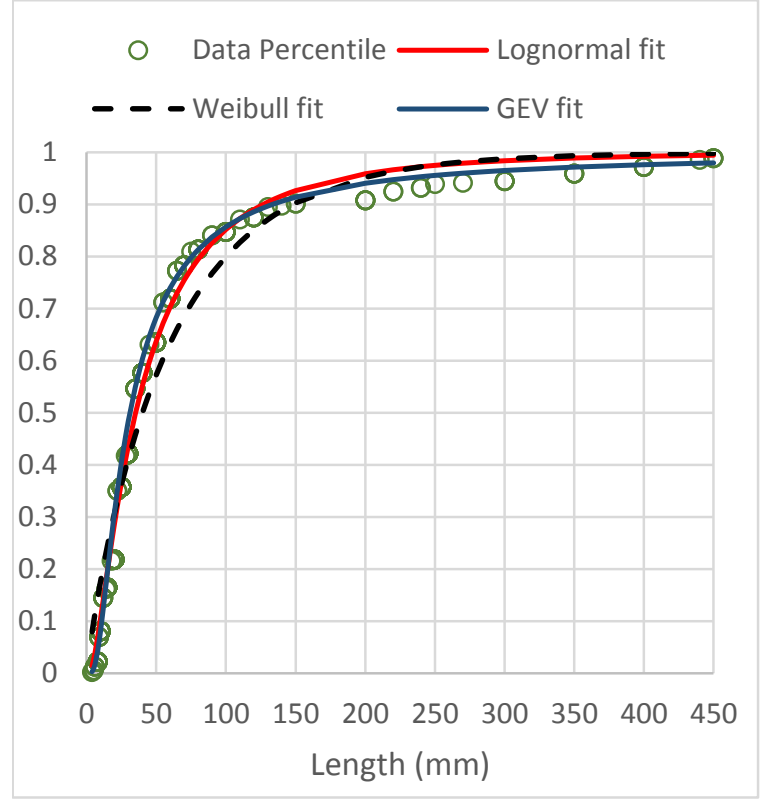

Figure 21 Ship \#3 Cavity length CDF

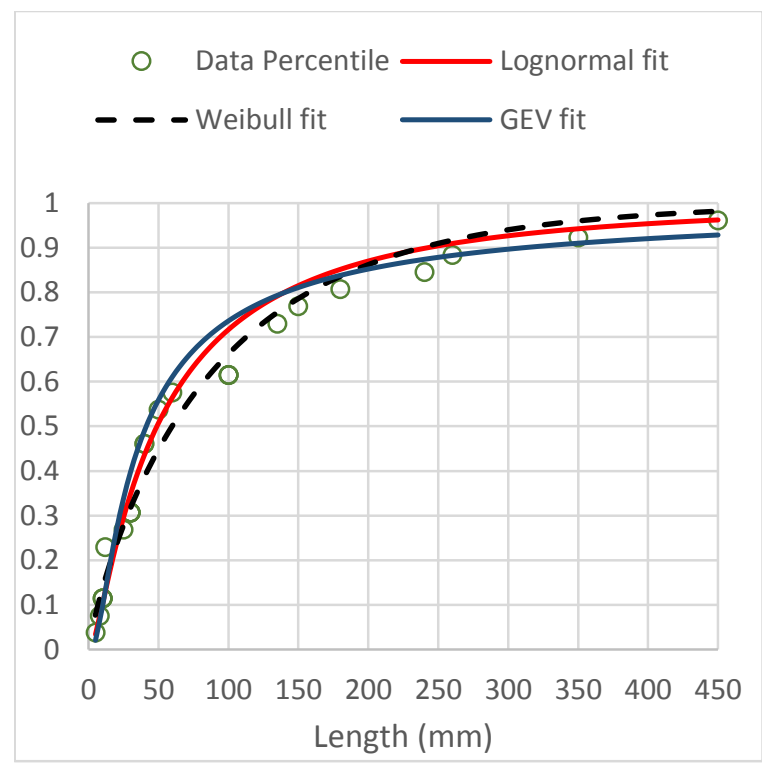

Figure 23 Ship \#3 LOP/LOF CDF 


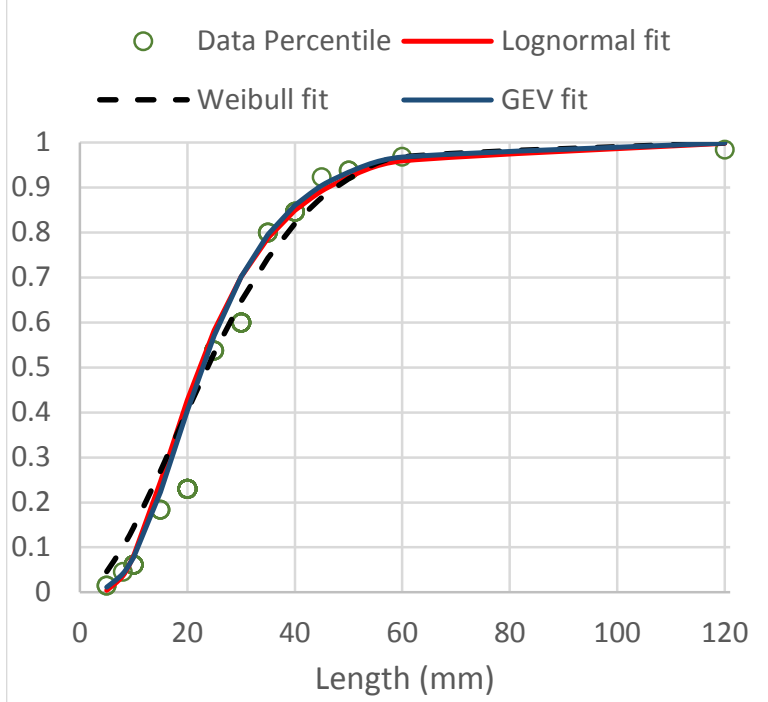

Figure 24 Ship \#2 Crack length CDF

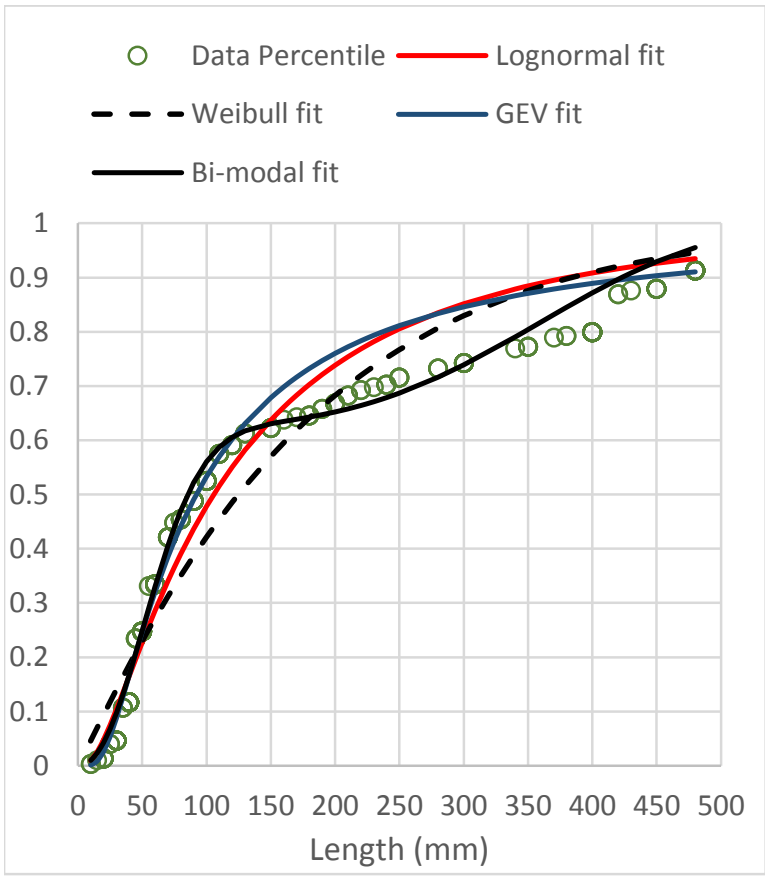

Figure 26 Ship \#2 Solid inclusion CDF

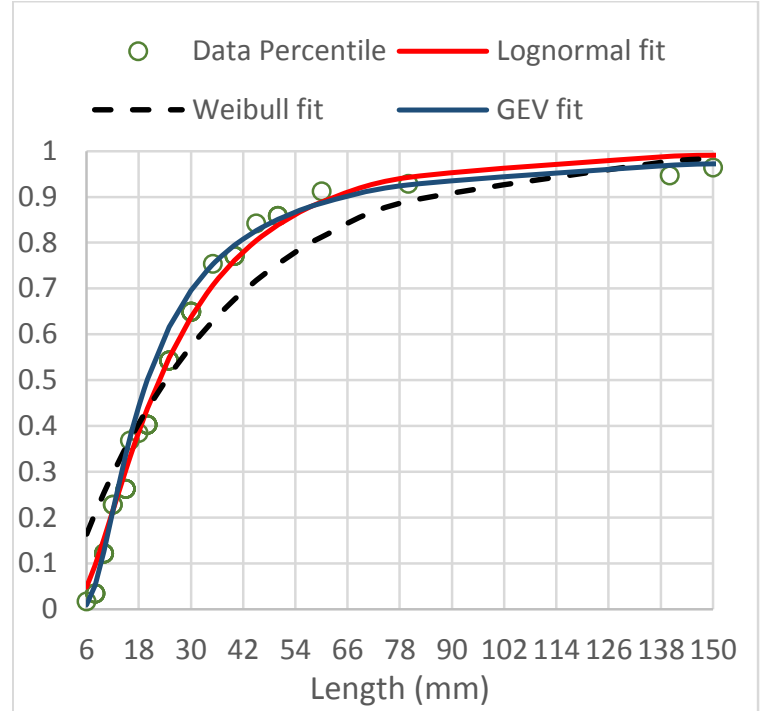

Figure 25 Ship \#3 Crack length CDF

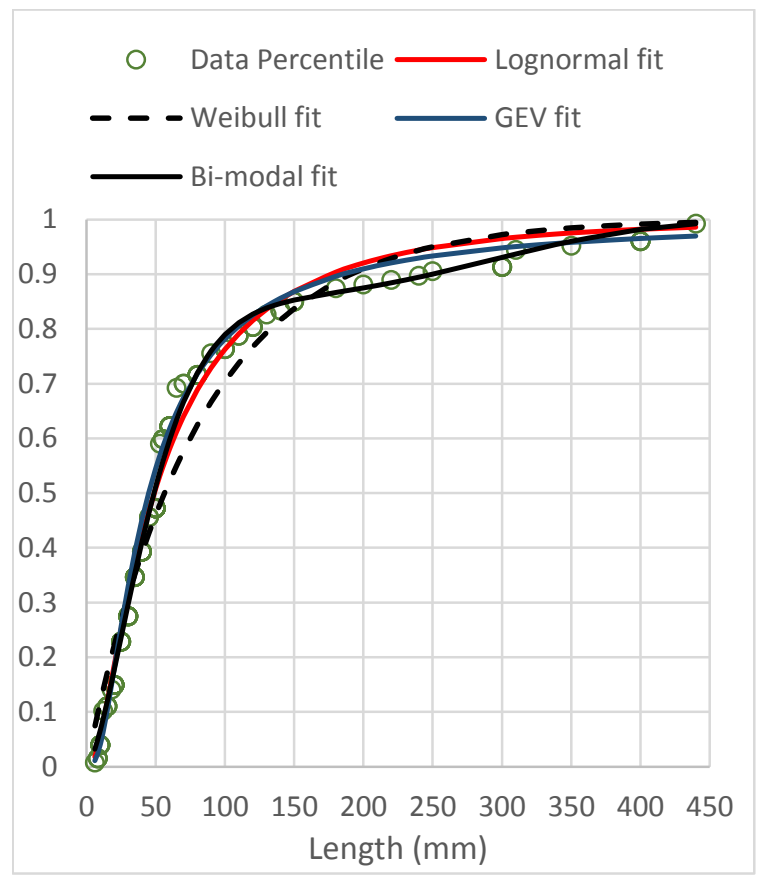

Figure 27 Ship \#3 Solid inclusion CDF

Defect length distributions from ship \#2 and \#3 are compared with those from literature in Figure 28 to Figure 31 . The crack lengths from the data are shorter than the data from literature except for the crack lengths reported by Kihara \& Susei [43], which may be ignored as the welding process and the NDT method and required quality level is unknown. The rest of the curves are for offshore structures and expected to be similar to ship structures. The 
LOP/LOF length from the ships are generally higher than those from literature. The solid inclusion length from the ships are similar to those reported by Kountouris \& Baker [33].
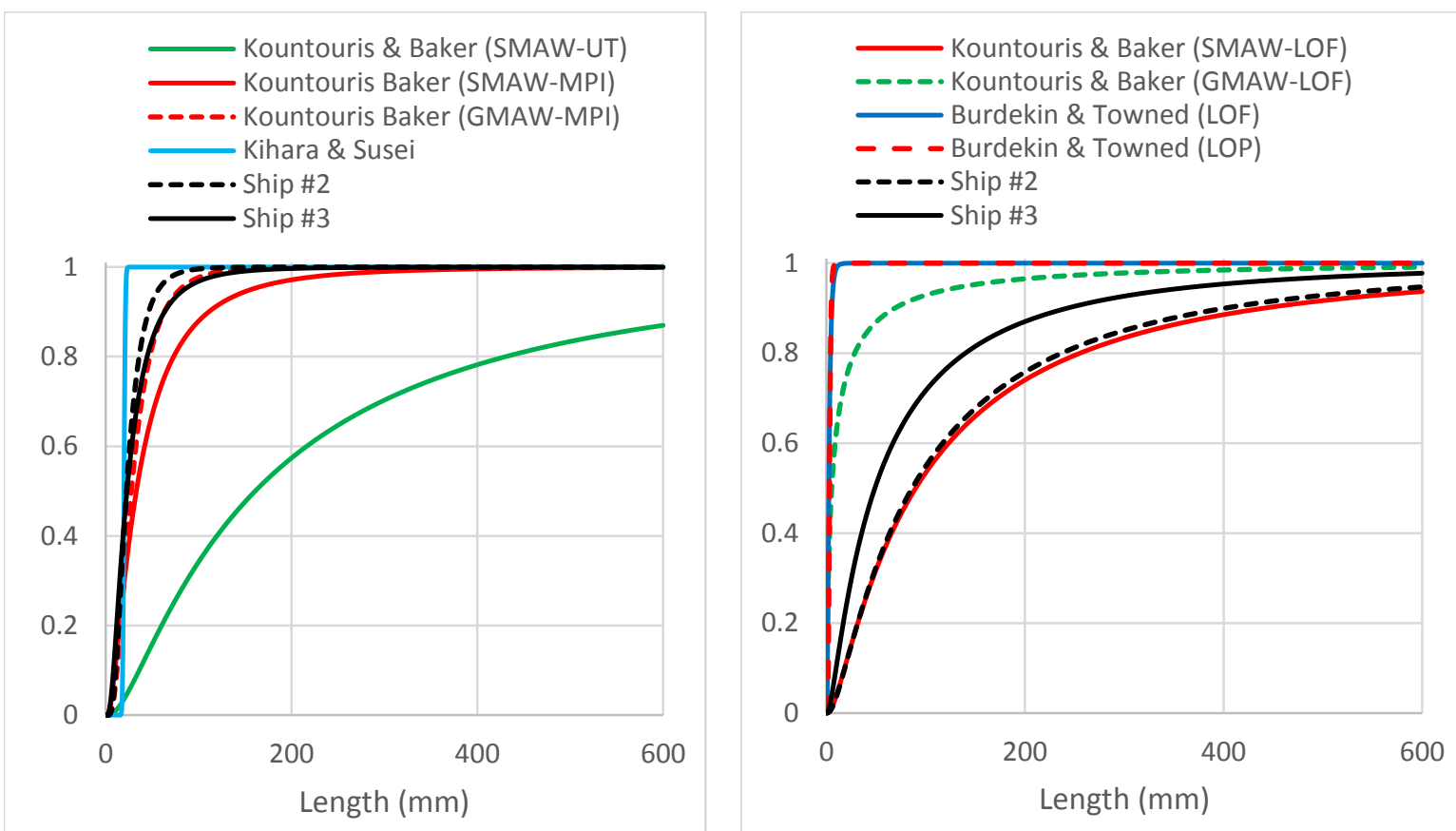

Figure 28 Crack length distribution

Figure 29 LOP and LOF length distribution
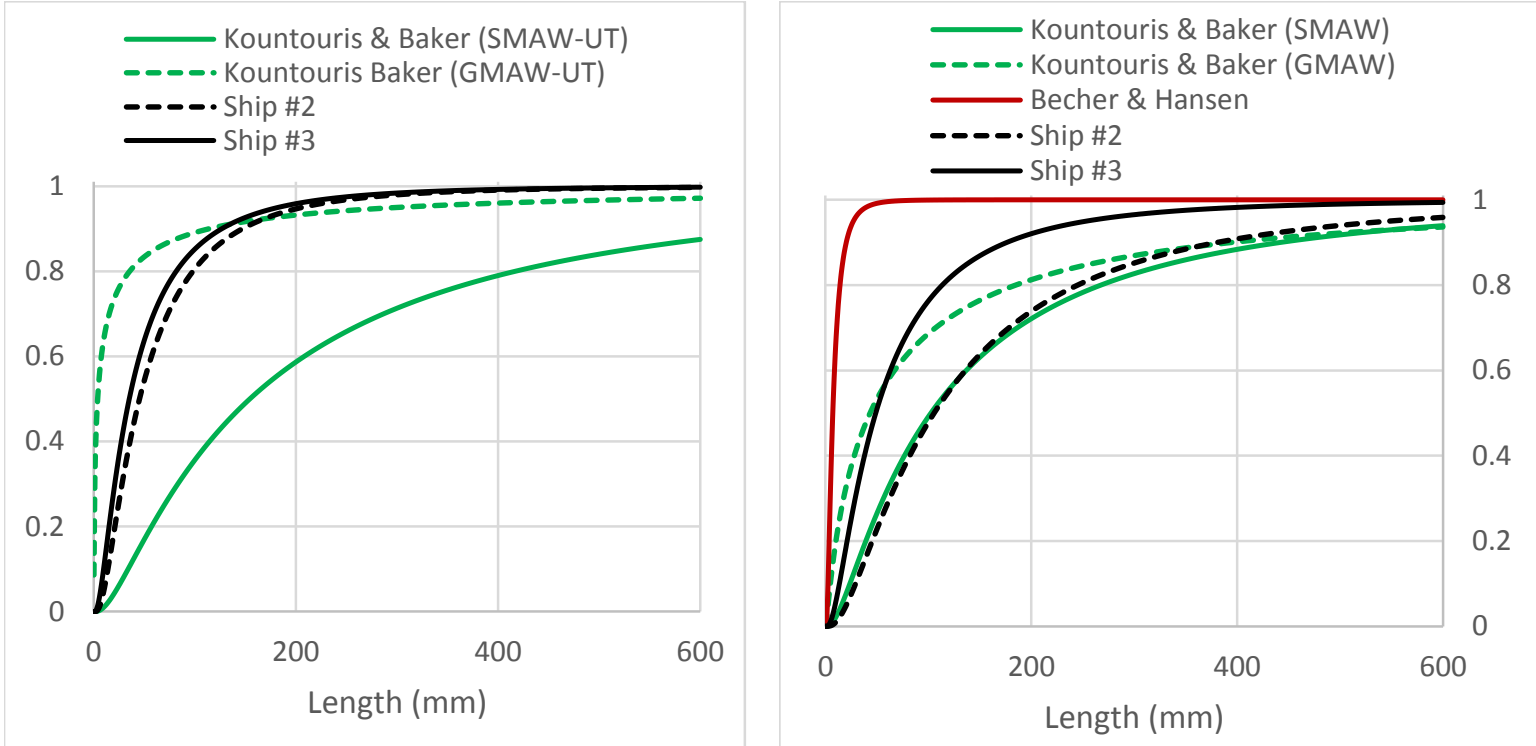

Figure 30 Cavity defects length distribution

Figure 31 Solid inclusion length distribution

Overall, the defect length distributions of the ships are relatively similar expect for the solid inclusion defects, but they are both meaningfully different from those found in the literature. 


\section{Discussion}

In this paper, defect length data from two ships, detected mainly by Radiography Testing (RT), have been analysed and it was found that median defect length ranged from $22 \mathrm{~mm}$ to 106 $\mathrm{mm}$. A broad review of published work on fabrication defect size was carried out and lognormal and Weibull distributions fit of defect length, height and aspect ratios were presented. It is concluded that the planar defect lengths of studied shipyards are significantly shorter than those from the literature indicating a possible better quality of welding, or welding process controls.

HLAW process shows a better quality in terms of defect occurrence than the other two processes. HLAW defect rates are 1 to 0.04 times the FCAW rates and 0.64 to 0.8 times SAW rates. This can show superior fatigue performance of joints made through HLAW. Opposite to ship \#2, FCAW defect rates in ship \#3 were higher than SAW although the sample size in ship \#2 is twice that of ship \#3 which makes the data from ship \#2 statistically more reliable.

All three-weld processes show similar relative distribution of defect types by producing a reasonably low amount of cracks (3\%-14\%) and high amount of cavities (35\%-58\%). The HLAW process produces considerably lower solid inclusions of $6 \%$ compared to $28 \%$ in SAW and $37 \%$ in FCAW. FCAW creates significantly lower LOF/LOP compared to the other two methods which may imply that it is a more reliable process as far as type of defect is concerned; LOF/LOP defects are planar defects and more likely to propagate under cyclic loading.

It was not possible to investigate the effect of joint type using the data from shipyards due to lack of information in the datasets, however, studies from literature suggest that defects in fillet welds are more common than in butt welds [20].

Within the range of thickness of $5.5 \mathrm{~mm}-22 \mathrm{~mm}$ no connection was found between plate thickness and defect frequency, or defect length.

Selection of NDT method was found to be affecting defect rate, defect size distribution and frequency of detected defect types significantly; Radiography Testing is less efficient in finding planar defects than Ultrasonic Testing. Planar defects are considered more damaging, in terms of fatigue and through-life structural integrity, hence, Ultrasonic Testing should be preferred over Radiography Testing where possible. If UT cannot be used due to thickness limitations (UT cannot be used for thicknesses below $8 \mathrm{~mm}$ ), Radiography Testing should be used in conjunction with a surface inspection method such as MPT or DPT.

In structural integrity assessment, planar defect rates are more important, particularly when the fracture mechanics approach is followed, but in weld process control, nonplanar defect 
rates can be equally important. They can be used to identify an out-of-control process. Therefore, when the defect rates are used for structural integrity assessment, UT should be preferred, whereas, when nonplanar defect rates are of interest, RT is a better choice. In any case, these rates should not be pooled together, as they may give inaccurate and misleading results. The defect rates should only be compared with each other if the effect of their NDT method reliability is accounted for.

The defect length distributions from two ships are significantly different except for the crack defects. This can be understood by comparing the median and $90^{\text {th }}$ values given in Table 15 . This may be partly because the sample sizes are significantly different; notice that the difference is much lower for cracks and cavities where the sample sizes are closer.

Planar defect length distributions from two studied cruise ships constructed in 2011 and 2012 are 3-7 times smaller than the offshore constructions from literature based on fabrication in the 1980 's. The difference could be due to inherent variation in welding quality, increased welding quality since 1980s, and the differences between welding processes and NDT techniques.

Another possible reason could be the effect of thickness; studied ships are made of very thin plates ranging from 5-10 $\mathrm{mm}$ in deck area and $16-22 \mathrm{~mm}$ in side-shell and bottom area. The offshore platform from [33] is believed to be fabricated from considerably thicker sections. The thicker the parent material the more weld passes the joint needs. Every weld pass introduces more heat input to the joint and consequently, more residual stress is formed. Weld joint residual stress is a key cause of the formation of weld pool cracks [47]. Also, each weld pass adds to the likelihood of internal cracks being left in the structure.

\section{Conclusions}

Weld defect frequency and size statistics are crucial inputs for structural integrity assessment based on fracture mechanics and also statistical quality control of welding processes. However, there is limited reliable information within the literature which can be applied to ship hull structures.

Defect type frequency statistics of three passenger ships built in early 2010's in a shipyard were analysed. It was found that HLAW process has significantly lower defect rates compared to FCAW and SAW, which can result in superior fatigue performance.

Defect length data were fitted to candidate probability distribution functions (PDFs) using the maximum likelihood estimate method. Generalised Extreme Value distribution (GEV), lognormal and Weibull distributions were found to offer the best distribution fit. 
It was found that the studied ship data has generally better welding quality in terms of defect rates and defect lengths compared to published data on offshore structures which could be due to increased welding quality since the 1980 s.

In the calculation of defect rates, it is suggested that the detection probability of the adopted NDT method is accounted for. Also, the defect rate of planar defects and nonplanar defects are recommended to be dealt with separately.

In this research, only defect length data, mainly collected by RT for quality control purposes, was available. However, for fracture mechanics assessment of ships made of thicker sections (above $10 \mathrm{~mm}$ ) in locations where formation of through thickness cracks has significant consequence, i.e. side shell or bottom structure, the defect height data is required, as well. Therefore, as an area of further research, it is recommended that such data be collected by appropriate methods such as UT.

Furthermore, the effect of NDT reliability on actual defect rates and initial defect size could be investigated by considering the POD curve over the whole range of defect sizes.

\section{Acknowledgments}

The research phase of this publication including data acquisition, conceptual discussions, internal review and preliminary data analysis was funded by Lloyd's Register Foundation, TWI Ltd and the University of Strathclyde which collaborated under the auspices of NSIRC. Lloyd's Register Foundation helps to protect life and property by supporting engineering-related education, public engagement and the application of research. The National Structural Integrity Research Centre (NSIRC), is a postgraduate engineering facility for industry-led research into structural integrity established and managed by TWI through a network of both national and international Universities.

The authors like to thank Dr Ujjwal Bharadwaj from TWI Ltd, and Mr Alessio Cendron from Lloyd's Register Italy for their valuable inputs and Mr Andrew MacdDonald global head of materials welding \& NDT at Lloyd's Register for his great support during this research.

\section{References}

1. BSI7608 (2015) Guide to fatigue design and assessment of steel products. London BSI Stand Publ

2. Béghin D, Hughes OF, Paik JK (2010) Ship structural analysis and design. Society of Naval Architects and Marine Engineers

3. Amirafshari P, Barltrop N, Bharadwaj U, et al (2018) A Review of Nondestructive 
Examination Methods for New-building Ships Undergoing Classification Society Survey. J Sh Prod Des 33:1-11

4. Jr. AFG (2003) Fundamentals Of Structural Integrity: Damage Tolerant Design And Nondestructive Evaluation. John Wiley \& Sons, Hoboken

5. Bharadwaj U, Wintle J (2011) Risk-Based Optimization of Inspection Planning in Ships. J Sh Prod Des 27:111-117

6. Barsoum Z, Jonsson B (2011) Influence of weld quality on the fatigue strength in seam welds. Eng Fail Anal 18:971-979

7. Lillemäe I, Remes H, Liinalampi S, Itävuo A (2016) Influence of weld quality on the fatigue strength of thin normal and high strength steel butt joints. Weld World 1-10

8. Jonsson MB, Samuelsson J, Marquis GB (2011) Development of weld quality criteria based on fatigue performance. Weld World 55:79-88

9. ISO B (2007) 6520-1 (2007)'Welding and allied processes: Classification of geometric imperfections in metallic materials.' Brussels

10. Mandal NR (2017) Ship Construction and Welding. Springer

11. Jonsson B, Dobmann G, Hobbacher AF, et al (2016) IIW Guidelines on Weld Quality in Relationship to Fatigue Strength. Springer International Publishing, Cham

12. BSI (2017) PD ISO/TS 20273:2017 Guidelines on weld quality in relationship to fatigue strength. 2017

13. British Standard (2019) BS 7910:2019. Br Stand Institutions, London 2019:

14. Hobbacher AF (2016) Recommendations for Fatigue Design of Welded Joints and Components. Springer International Publishing, Cham

15. Boekholt R (1996) Welding Mechanisation and Automation in Shipbuilding Worldwide: Production Methods and Trends Based on Yard Capacity. Abington Publishing

16. Kobelco (2011) State-of-the-art automatic arc welding processes meet the latest shipbuilding requirements. Kobelco Weld today 14 :

17. Olsen FO (2009) Hybrid laser-arc welding. Elsevier

18. Zhao W, Stacey A (2002) Review of Defect Distributions for Probabilistic Structural Integrity Assessment. In: ASME 2002 21st International Conference on Offshore Mechanics and Arctic Engineering. pp 607-619

19. Wintle J (2002) A review of methods for determining the frequency and size distribution of welding flaws in steel fabrications

20. Marcello Consonni CFW (2012) Repair rates in welded construction - an analysis of 
industry trends. Weld Cut 33-35

21. Rummel WD, Matzkanin GA (1997) Nondestructive evaluation (NDE) capabilities data book (NTIAC: DB-97-02). NTIAC 625

22. DNV (2015) DNVGL-RP-C210-Probabilistic methods for planning of inspection for fatigue cracks in offshore structures

23. Baker, Kountouris, Ohmart (1988) Weld Defects in An Offshore Structure, A Detailed Study. In: Int. Conf. On Behavior of Offshore Structures

24. Marshall W (1982) An assessment of the integrity of PWR pressure vessels

25. Bokalrud T, Karlsen A (1982) Probabilistic fracture mechanics evaluation of fatigue failure from weld defects in butt welded joints. In: Proc. Conf. on fitness for purpose validation of welded constructions

26. Rogerson JH, Wong WK (1982) Weld defect distributions in offshore structures and their influence on structural reliability. Soc Pet Eng AIME, Pap;(United States) 2:

27. Moan T, Vårdal OT, Hellevig N-C, Skjoldli K (1997) In-service observations of cracks in north sea jackets. A study on initial crack depth and POD values. In: PROCEEDINGS OF THE INTERNATIONAL CONFERENCE ON OFFSHORE MECHANICS AND ARCTIC ENGINEERING. pp 189-198

28. Baker M, Stanley I (2008) Assessing and modelling the uncertainty in fatigue crack growth in structural steels. Heal Saf Exec Res Rep RR643, Norwich

29. Harris DO (1995) Probabilistic fracture mechanics. In: Probabilistic structural mechanics handbook. Springer, pp 106-145

30. Amirafshari P (2017) APPLICATION OF PROBABILISTIC FRACTURE MECHANICS IN RISK BASED NON DESTRUCTIVE EXAMINATION OF NEW BUILDING SHIPS. In: 3rd NSIRC Conference

31. Wallin K (2011) Fracture toughness of engineering materials: Estimation and application. EMAS publishing

32. Zhao W, Stacey A, Prakash P (2002) Probabilistic models of uncertainties in fatigue and fracture reliability analysis. In: ASME 2002 21st International Conference on Offshore Mechanics and Arctic Engineering. pp 557-578

33. Kountouris IS, Baker MJ (1989) Defect assessment: analysis of the dimensions of defects detected by ultrasonic inspection in an offshore structure. Imperial College of Science and Technology Engineering Structures Laboratories

34. Naess A (1985) Fatigue handbook: offshore steel structures

35. Lassen T, Recho N (2013) Fatigue life analyses of welded structures: flaws. John Wiley \& Sons 
36. Glenn IF (1999) Fatigue Resistant Detail Design Guide for Ship Structures. Ship Structure Committee

37. Bäckström M, Kivimaa S (2009) Estimation of crack propagation in a passenger ship's door corner. Ships Offshore Struct 4:241-251

38. Garwood SJ (2001) Investigation of the MV KURDISTAN Casualty. In: Failure Analysis Case Studies II. Elsevier, pp 117-138

39. Townend PH (1980) Distribution of Lack of Fusion and Lack of Penetration Defects in Tube to Tube $90^{\circ}$ and $45^{\circ}$ Joints Produced by Manual Metal Arc Welding of BS 4360 Grade 50D Steel. University of Manchester Institute of Science and Technology

40. Becher PE, Hansen B (1974) Statistical evaluation of defects in welds and design implications. Riso Danish Atomic energy commission research establishment

41. Kountouris IS, Baker MJ (1989) Defect assessment: analysis of the dimensions of defects detected by magnetic particle inspection in an offshore structure. Imperial College of Science and Technology Engineering Structures Laboratories

42. Burdekin FM, Towned PH (1981) Reliability Aspects of Fracture on Stress Concentration Regions in Offshore Structures, Integrity of Offshore Structures, 2nd Int. In: Symp., Glasgow

43. Kihara $\mathrm{H}, \mathrm{Oba} \mathrm{H}$, Susei S (1971) Precautions for avoidance of fracture of pressure vessels. In: International Conference on Practical Application of Fracture Mechanics to Pressure Vessel Technology, Institute of Mechanical Engineering, London

44. Gurney TR (1979) Fatigue of welded structures, 2nd ed. Cambridge University Press, Cambridge

45. BCSA (2012) Guide to Weld Inspection for Structural Steelwork. The British Constructional Steelwork Association Ltd, London

46. Amirafshari P (2019) Optimising Non-destructive Examination of newbuilding ship hull structures by developing a data-centric risk and reliability framework based on fracture mechanics. University of Strathclyde

47. Singh R (2016) Chapter 8 - Weld Defects and Inspection. In: Singh R (ed) Applied Welding Engineering (Second Edition), Second Edi. Butterworth-Heinemann, pp 277295 